\title{
Economia Social e Pública
}

LUCCA SIMEONI PAVAN

(Organizador)
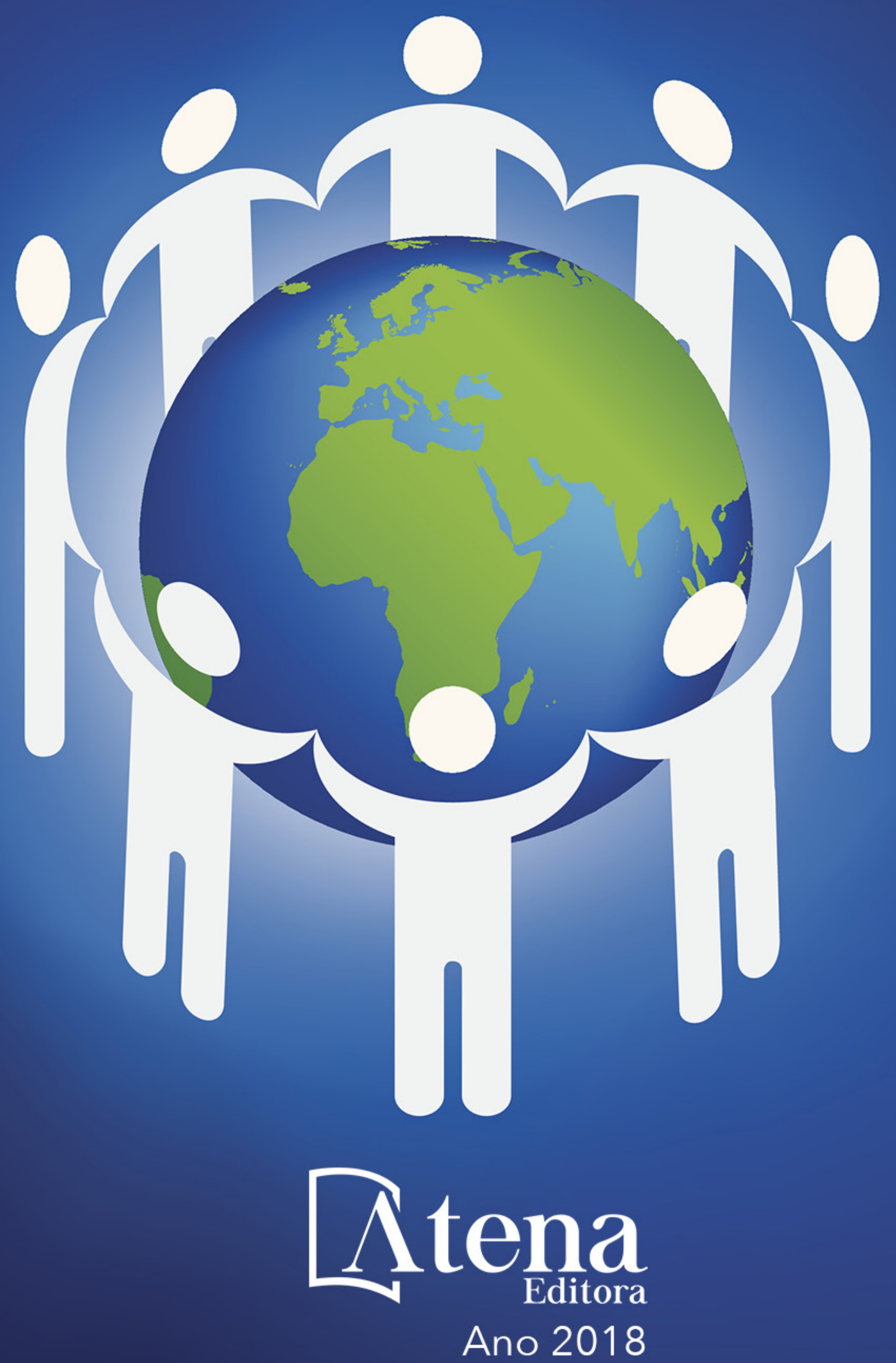


\section{Lucca Simeoni Pavan}

(Organizador)

\section{Economia Social e Pública}

Atena Editora

2018 
2018 by Atena Editora

Copyright (C) da Atena Editora

Editora Chefe: Prof $^{\mathrm{a}} \mathrm{Dr}^{\mathrm{a}}$ Antonella Carvalho de Oliveira

Diagramação e Edição de Arte: Geraldo Alves e Natália Sandrini

Revisão: Os autores

\section{Conselho Editorial}

Prof. Dr. Alan Mario Zuffo - Universidade Federal de Mato Grosso do Sul

Prof. Dr. Álvaro Augusto de Borba Barreto - Universidade Federal de Pelotas

Prof. Dr. Antonio Carlos Frasson - Universidade Tecnológica Federal do Paraná

Prof. Dr. Antonio Isidro-Filho - Universidade de Brasília

Prof $^{\mathrm{a}} \mathrm{Dr}^{\mathrm{a}}$ Cristina Gaio - Universidade de Lisboa

Prof. Dr. Constantino Ribeiro de Oliveira Junior - Universidade Estadual de Ponta Grossa

Prof $^{a}$ Dr $^{a}$ Daiane Garabeli Trojan - Universidade Norte do Paraná

Prof $^{a}$ Dr $^{a}$ Deusilene Souza Vieira Dall'Acqua - Universidade Federal de Rondônia

Prof. Dr. Eloi Rufato Junior - Universidade Tecnológica Federal do Paraná

Prof. Dr. Fábio Steiner - Universidade Estadual de Mato Grosso do Sul

Prof. Dr. Gianfábio Pimentel Franco - Universidade Federal de Santa Maria

Prof. Dr. Gilmei Fleck - Universidade Estadual do Oeste do Paraná

Prof $^{a}$ Dr $^{\text {a }}$ Girlene Santos de Souza - Universidade Federal do Recôncavo da Bahia

Prof $^{\mathrm{a}} \mathrm{Dr}^{\mathrm{a}}$ Ivone Goulart Lopes - Istituto Internazionele delle Figlie de Maria Ausiliatrice

Prof. Dr. Julio Candido de Meirelles Junior - Universidade Federal Fluminense

Prof. Dr. Jorge González Aguilera - Universidade Federal de Mato Grosso do Sul

Prof ${ }^{a} \mathrm{Dr}^{\mathrm{a}}$ Lina Maria Gonçalves - Universidade Federal do Tocantins

Prof $^{a}$ Dr $^{a}$ Natiéli Piovesan - Instituto Federal do Rio Grande do Norte

Prof $^{a}$ Dr $^{\mathrm{a}}$ Paola Andressa Scortegagna - Universidade Estadual de Ponta Grossa

Prof $^{a}$ Dr $^{\mathrm{a}}$ Raissa Rachel Salustriano da Silva Matos - Universidade Federal do Maranhão

Prof. Dr. Ronilson Freitas de Souza - Universidade do Estado do Pará

Prof. Dr. Takeshy Tachizawa - Faculdade de Campo Limpo Paulista

Prof. Dr. Urandi João Rodrigues Junior - Universidade Federal do Oeste do Pará

Prof. Dr. Valdemar Antonio Paffaro Junior - Universidade Federal de Alfenas

Prof $^{\mathrm{a}} \mathrm{Dr}^{\mathrm{a}}$ Vanessa Bordin Viera - Universidade Federal de Campina Grande

Prof. Dr. Willian Douglas Guilherme - Universidade Federal do Tocantins

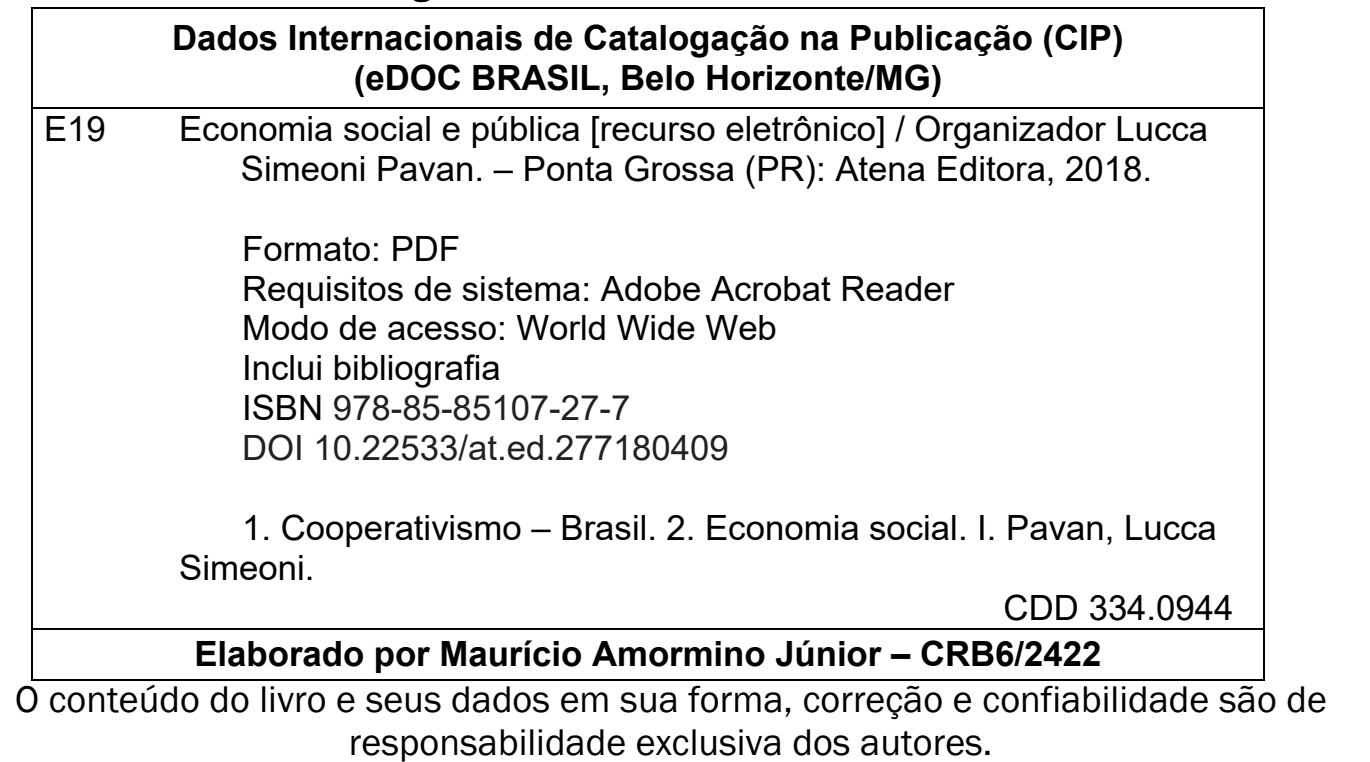

2018

Permitido o download da obra e o compartilhamento desde que sejam atribuídos créditos aos autores, mas sem a possibilidade de alterá-la de nenhuma forma ou utilizá-la para fins comerciais.

www.atenaeditora.com.br

E-mail: contato@atenaeditora.com.br 


\section{QUADRO TEÓRICO DE APOIO À ATUAÇÃO DE EXTENSIONISTAS PARA O FORTALECIMENTO DA ECONOMIA SOLIDÁRIA}

Newton José Rodrigues da Silva Zootecnista, Dr., Extensionista da Coordenadoria de Assistência Técnica Integral (CATI). Integrante do Fórum de Economia Solidária da Baixada Santista. E-mail: newtonrodrigues@cati.sp.gov.br.

Abelardo Gonçalves Pinto Engenheiro agrônomo, Dr., Extensionista. Associação Paulista de Extensão Rural (APAER).

Edna Ferreira Maddarena Lopez Médica-veterinária, Dra., Extensionista da Coordenadoria de Assistência Técnica Integral (CATI).

Olivier Mikolasek

Zootecnista, Dr., Pesquisador do Centre de Coopération Internationale en Recherche pour le Développement (CIRAD).

RESUMO: $O$ presente trabalho emerge da necessidade de oferecer a estudantes e profissionais da extensão rural um conjunto de conceitos e referenciais teóricos que se fundamentam no construtivismo para que orientem uma atuação que contemple a elaboração e execução de projetos com base na participação e necessidades dos diferentes grupos que integram o público da extensão para a construção e fortalecimento dos empreendimentos econômicos solidários. Economias de grandeza, sociologia da tradução e economia de proximidade são referenciais mobilizados para a construção do quadro teórico. As economias de grandeza possibilitam interpretar as lógicas de ação dos atores implicados em determinado problema. A sociologia da tradução viabiliza a compreensão dos processos de construção de redes sociotécnicas que viabilizam os empreendimentos. A economia de proximidade é uma forma de organização econômica que se fundamenta em reciprocidades, base da economia solidária e do desenvolvimento local. Aadoção desse quadro teórico pelas instituições de ensino pode representar um importante passo para formação de profissionais da extensão para atuarem com fundamentação no apoio à economia solidária.

PALAVRAS-CHAVE: extensão rural, economia solidária, sociologia da tradução, economias de grandeza, economia de proximidade

ABSTRACT: The present work emerges from the need to offer students and professionals of rural extension a set of concepts and theoretical references that are based on constructivism to guide an action that contemplates the elaboration and execution of projects based on the participation and needs of the different groups that integrate the public of the extension for the construction and strengthening of the supportive economic enterprises. Economies of greatness, sociology of translation and economy 
of proximity are system of references mobilized for the construction of the theoretical framework. The economies of greatness make it possible to interpret the action logics of the actors involved in a given problem. The sociology of translation allows the understanding of the processes of construction of socio technical networks that make feasible the enterprises. Proximity economy is a form of economic organization based on reciprocity, the basis of supportive economy and local development. The adoption of this theoretical framework by educational institutions can represent an important step for the training of extension professionals to act with support to the supportive economy.

KEYWORDS: rural extension, solidarity economy, sociology of translation, economies of greatness, proximity economy

\section{I INTRODUÇÃO}

O presente trabalho emergiu da necessidade de oferecer a alunos e profissionais da extensão rural e pesqueira um conjunto de conceitos e referenciais teóricos que se fundamentam no construtivismo para uma atuação que contemple a elaboração e execução de projetos para a construção e fortalecimento dos empreendimentos econômicos solidários com base na participação e necessidades das diferentes pessoas e segmentos que integram o público da extensão. A necessidade de fazer a presente abordagem fundamenta-se em estudos que identificaram o distanciamento da prática extensionista do conceito de sustentabilidade. Além disso, apontam o caráter difusionista de projetos e ações que comumente são executados.

A deficiência na formação de graduandos das ciências agrárias é notória quanto aos princípios, valores e possibilidades da economia solidária, que raramente é abordada nas escolas. Assim, muitos profissionais da extensão não conseguem identificar que o assessoramento que fazem às associações e cooperativas de agricultores e pescadores poderia fortalecer a autogestão. Como o ensino é focado para a utilização do difusionismo como forma de elaboração de projetos, disponibilização de tecnologia e gestão voltada para o mercado, comumente apenas parte do público potencialmente beneficiário das ações de extensão se beneficia de fato dos trabalhos dos extensionistas. O quadro se agrava pelo fato de o difusionismo não proporcionar a construção de redes sociotécnicas que portam os projetos, possibilitam a cooperação e reciprocidade entre diferentes atores sociais e promovem o desenvolvimento territorial. O difusionismo viabiliza inovações empresariais e o construtivismo as inovações sociais, o que é mais adequado quando se trata de grupos de produtores, prestadores de serviços que organizam finanças solidárias ou comercializam. Emerge, assim, a necessidade de caracterizar o difusionismo e disponibilizar um conjunto de referenciais teóricos e conceitos relacionados com o construtivismo para que os extensionistas tenham uma outra forma de atuação e possam apoiar a viabilização de empreendimentos econômicos solidários como resultado da construção de redes de 
cooperação. Como existe uma vasta bibliografia que explica a economia solidária, não será feita uma abordagem com conceituação, princípios, valores ou histórico da sua evolução no Brasil.

O primeiro tópico do texto relaciona-se com o conceito de extensão. Afinal, de que estamos falando? São abordados aspectos semântico e histórico. Posteriormente, fazse a caracterização dos modelos difusionista e construtivista de atuação, assim como a especificação dos níveis de participação na elaboração de projetos de economia solidária. Em seguida, é apresentado um conjunto de referenciais teóricos que podem ser inseridos nas grades curriculares dos cursos de graduação e pós-graduação, assim como naqueles referentes aos pré-serviços dos profissionais da extensão. O primeiro referencial abordado denomina-se economias de grandeza. Durante o processo de organização de pescadores artesanais e agricultores familiares em associações, cooperativas ou mesmo em grupos informais de compra de insumos ou comercialização, por exemplo, comumente emergem controvérsias entre os participantes. Esses fenômenos são entendidos como divergências pautadas por interesses que impedem o estabelecimento de acordos para que as pessoas trabalhem de forma coordenada. Assim, para um extensionista, torna-se de fundamental importância conhecer as lógicas de ação de cada um dos envolvidos no problema, com a intenção de construir estratégias para que haja cooperação e, consequentemente, se alcance os objetivos propostos. Afinal, as organizações existem somente quando as pessoas cooperam.

O segundo referencial teórico abordado é a sociologia da tradução. A sua compreensão permitirá ao extensionista identificar os fatores responsáveis pelo fracasso ou sucesso de um grupo, assim como pautar a sua atuação na construção de redes sociotécnicas que viabilizam os empreendimentos econômicos solidários.

A valorização dos recursos e talentos locais é uma forma aconselhável para a promoção de desenvolvimento com base na economia solidária. Para melhor compreensão das proximidades que podem ser ativadas para que se alcance esse objetivo, apresenta-se, por fim, as bases da economia de proximidade. Trata-se de uma forma de organização da economia fundamentada na relação direta entre fornecedores e consumidores, assim como entre os empreendimentos locais que integram a sua dinâmica. O seu objetivo é promover bem-estar valorizando o território para e pelos habitantes, os atores locais.

Dessa forma, o presente artigo tem o objetivo de apresentar um conjunto de conceitos e referenciais teóricos que podem ser disponibilizados para alunos e profissionais da extensão para que atuem com fundamentação no construtivismo, o que possibilitará irem além da simples disponibilização de tecnologia no exercício das suas atividades. 


\section{I METODOLOGIA}

Utilizou-se como base para elaboração da problemática as dissertações realizadas por Pinto (1998) e Lima (2001) que abordam as características de atuação e perfis profissionais dos extensionistas da rede pública do Estado de São Paulo, assim como houve fundamentação em Silva (2008), que estudou a forma de atuação destes profissionais no desenvolvimento da aquicultura nos Estados de Santa Catarina e São Paulo, com o objetivo de qualificar as ações como difusionistas ou construtivistas e relacioná-las com os resultados obtidos. Os autores do presente artigo integram equipes de extensão rural no Estado de São Paulo onde assumem um compromisso de atuação nos moldes da pesquisa participante que, segundo Lüdke e André (2013), combina simultaneamente a análise documental, a entrevista respondentes e informantes, a participação e observação direta e a instrospecção. Além disso, foram analisadas as grades curriculares de nove escolas de nível superior de Santa Catarina, Rio de Janeiro e São Paulo que oferecem cursos de ciências agrárias.

\section{I QUADRO TEÓRICO: CONCEITOS E REFERENCIAIS}

\subsection{Extensão: uma abordagem semântica}

Extensão é um termo comumente utilizado para se referir às ações de difusão de conhecimentos. Existem duas denominações amplamente empregadas que a qualifica principalmente quanto às instituições e agentes que a fazem: extensão universitária e extensão rural. No primeiro caso os serviços são oferecidos pelas universidades e são elaborados e executados por professores e alunos. No segundo caso, a extensão é realizada por órgãos especializados ou ONGs. Quando as ações de extensão são voltadas especificamente para os aquicultores, utiliza-se o termo extensão em aquicultura para se referir aos serviços prestados. Quando são considerados os pescadores como público-alvo, usa-se a expressão extensão pesqueira.

Porém, há os processos de educação não formal coordenados pela extensão, fundamentados na participação e valorização dos conhecimentos dos produtores, que proporcionam aprendizagem também para os extensionistas, e não se resumem à difusão de conhecimentos, como normalmente a extensão é compreendida e tratada. Para qualificar este tipo de atuação da extensão, Freire (1980) afirma que há quem utilize o termo extensão educativa, pois o extensionista não atua como um difusor de conhecimentos, mas como educador-educando, que faz interagir os seus conhecimentos com os dos produtores para a construção de outra realidade, não havendo imposição de saberes. Para o referido autor, a qualificação da extensão como educativa não minimiza o sentido do ato de estender conhecimentos do termo, pois sugere a existência de relações verticais em que o produtor é tratado como uma 
pessoa que não possui conhecimentos, mas apenas como receptor.

Independente da questão semântica, a expressão extensão é consagrada em diferentes países, independente de os processos de disponibilização de conhecimentos estarem associados a modelos de difusão de conhecimentos, transferência de tecnologia ou se a atuação do extensionista está relacionada com metodologias educativas, que valorizam a participação e o conhecimento dos produtores.

\subsection{Extensão universitária}

Van der Ban e Hawkins (1998) afirmam que a extensão universitária, ou extensão da universidade, foi o primeiro tipo de extensão que surgiu, em 1840, na Inglaterra. Porém, as primeiras ações práticas naquele país se deram somente entre 1867 e 1868, quando a Universidade de Cambridge ministrou conferências para mulheres, associações e clubes de trabalhadores no Norte da Inglaterra. Em 1873, a referida universidade formalizou a criação do que foi denominado de centros de extensão, para estender conhecimentos a lugares distantes do seu entorno. Posteriormente, o modelo foi adotado pela Universidade de Londres, em 1876, e Universidade de Oxford, em 1878. Portanto, pode-se definir extensão universitária como as ações implementadas sob a supervisão de universidades com o objetivo de estender conhecimentos a produtores, técnicos, associações, comunidades etc. As ações de extensão universitária são de grande importância para a disponibilização dos conhecimentos gerados pelos pesquisadores, professores e alunos.

Nunes (2009) aborda a trajetória da extensão universitária no Brasil desde 1889 e a associa com a incubação de empreendimentos econômicos solidários a partir de 1995 com a criação da Incubadora Tecnológica de Cooperativas Populares da Universidade Federal do Rio de Janeiro. A autora afirma que somente a região Sul do Brasil se destaca na incubação de empreendimentos vinculados à agricultura familiar e agricultura periurbana. Esse fato ressalta a necessidade de as universidades implantarem incubadoras voltadas para as associações e cooperativas de agricultores familiares e pescadores artesanais. $O$ assessoramento articularia disponibilização de tecnologia, gestão e fortalecimento dos valores e princípios da economia solidária. Porém, as incubadoras deveriam se perenes e atuar em rede, principalmente com os serviços de extensão rural.

\subsection{Extensão rural: histórico e conceitualização}

A extensão rural foi iniciada na Irlanda em 1845, como forma sistematizada de assistência técnica, para a difusão de conhecimentos, com o objetivo de atender às necessidades reais de agricultores e suas famílias que passavam por grandes dificuldades. Naquele país, entre o referido ano e 1852, houve uma doença na cultura da batata, que era a base da alimentação da população. A fome e, como consequência 
as doenças, provocaram a morte de 1 milhão de pessoas e expressiva emigração (Colombo, 2000; Caporal, 1991).

Outro evento que significa um marco na trajetória da extensão rural foi a criação do Sistema Cooperativo de Extensão (Cooperative Extension Service) nos Estados Unidos da América em 1914. Porém, Silva e Oliveira (2010) afirmam que em 1785 já havia ações que podem ser consideradas como extensão nos estados da Carolina do Sul e na Filadélfia. Grupos da sociedade atuavam para a "Promoção e Progresso da Agricultura", com a oferta de prêmios pelos progressos obtidos na área, por meio do financiamento de palestras e publicação das realizações de seus integrantes.

O Sistema Cooperativo de Extensão é uma referência, pois a sua organização se mantém desde a sua criação, sendo integrado pelo governo federal, por meio do Departamento de Agricultura (USDA), pelos estados, por meio das universidades, e pelos governos locais, havendo em sua estrutura um expressivo número de voluntários. Ramussen (1989), apud Silva e Oliveira (2010), destaca a missão desse Sistema: "O Sistema Cooperativo de Extensão ajuda as pessoas a melhorar sua vida por meio de um processo educacional que usa conhecimento científico focado nas necessidades". Porém, Leeuwis (2006) apud Silva e Oliveira (2010), afirma que ainda há pesquisadores que insistem no modelo difusionista, unidirecional, onde eles geram o conhecimento e o agricultor limita-se a realizar ou não as inovações.

A compreensão da organização e atuação da extensão rural dos EUA é relevante, pois foi este país que deu respaldo técnico e financeiro para a introdução da extensão rural na América Latina. Apesar de o modelo norte-americano funcionar integrado com a universidade, em conjunto com a pesquisa e ensino, essa característica não foi implantada na América Latina (Vela e Hegedus, 1999). Estes autores periodizaram a trajetória da extensão rural na América Latina, considerando o modelo de desenvolvimento rural em curso e as características de atuação dos serviços de extensão rural. O primeiro período é compreendido entre os anos de 1945 e 1960. Evidenciam que o interesse dos EUA em financiar a implantação da extensão rural na América Latina era criar um serviço funcional para mudar a base tecnológica da agricultura e, com isso, dinamizar ainda mais a indústria norte-americana de insumos. Além disso, as inovações mecânicas representaram a troca de homens por máquinas, o que promoveu fluxos migratórios com a liberação de mão de obra para as áreas urbanas, o que, intencionalmente, permitiu a expansão da indústria nos países latinos. Fonseca (1985) afirma que o papel da extensão no meio rural no Brasil era de um instrumento capacitado para garantir que o homem rural entrasse no ritmo e na dinâmica da sociedade de mercado e, assim, pudesse consumir mais adubos, vacinas e equipamentos para continuar produzindo e, consequentemente, consumindo. Por outro lado, mulheres extensionistas, sobretudo com formação em economia doméstica, trabalhavam com a família do produtor, com o objetivo de melhorar a qualidade de vida.

A extensão rural possui diferentes definições, que variam de acordo com o modelo de desenvolvimento que está em curso. Para esse período (1945 - 1960), 
pode-se utilizar com segurança a definição de Olinger (1996): "Processo educativo realizado com e em favor das famílias rurais para difundir informações úteis e práticas sobre assuntos relacionados com a agricultura e economia doméstica e encorajar a aplicação das mesmas". Dessa forma, o extensionista atuava como indutor de mudanças de comportamento, mas havia ações caracterizadas como assistencialismo. Assim, Rodrigues (1997) caracterizou esse período como humanista assistencialista.

Entre as décadas de 1960 e 1980, houve o aprofundamento das ações difusionistas de tecnologias de uso intensivo de capital. O objetivo era modernizar o processo produtivo e aumentar a produtividade da terra. O crédito rural era usado de forma orientada, voltado para os produtos de exportação. A extensão não atuava para que os agricultores se organizassem e os trabalhos de promoção social junto às famílias dos produtores foram abandonados. Hegedus (1999) afirma que os produtores eram tratados pelos extensionistas como se fossem uma população homogênea e não havia a preocupação em conhecer quais eram as necessidades e motivações de cada grupo. Enfim, a oferta de assistência técnica não levava em conta a demanda. A adoção de novas técnicas era baixa, considerando o conjunto dos produtores, e os serviços não recebiam pressão para serem mais eficientes. Para Rodrigues (1997) trata-se de um período caracterizado pelo difusionismo produtivista. Porém, emergiu a crítica ao modelo de extensão em curso, realizada principalmente por Paulo Freire e pesquisadores que trabalhavam no Instituto Interamericano de Ciências Agrícolas (IICA). A proposta é que fosse criado um modelo extensão rural capaz de construir relações horizontais entre extensionistas e produtores. A extensão estaria além da difusão de resultados tecnológicos da pesquisa, pois se buscava desenvolver processos participativos, fundamentados na educação, com a valorização dos conhecimentos dos produtores, com a problematização da realidade e construção coletiva das soluções, sejam elas de ordem técnica ou organizacional. Leite et al. (2012) afirmam que nos anos 1980 a mensagem de Paulo Freire influenciou muitos extensionistas, mas a chamada comunicação horizontal ou participativa esbarrava na formação dos extensionistas, no corporativismo estatal e nos interesses capitalistas.

Vela e Hegedus (1999) registram que nas décadas de 1980 e 1990 houve uma diminuição dos recursos empenhados para a extensão rural na América Latina. Porém, havia novos desafios lançados, principalmente a partir do Relatório Brundtland, de 1987, quando emergiu o conceito de sustentabilidade. Os fatores que motivaram o modelo de desenvolvimento adotado pelos países industrializados ou em desenvolvimento foram o uso excessivo dos recursos naturais sem considerar a capacidade de suporte dos ecossistemas e a incompatibilidade entre desenvolvimento sustentável e os padrões de produção e consumo vigentes. O Relatório aponta que o desenvolvimento deveria responder às necessidades do presente sem comprometer a capacidade das gerações futuras de suprir as suas próprias necessidades. Assim, colocava-se em debate o modelo de desenvolvimento estimulado na América Latina pela extensão rural. No Brasil, a Federação dos Trabalhadores da Assistência Técnica e do Setor 
Público Agrícola do Brasil (FASER) propôs uma nova definição para extensão rural, fundamentada na reflexão elaborada por Paulo Freire e que atendia as necessidades do conceito de sustentabilidade: "Processo educativo que se propõe a contribuir de forma participativa com o desenvolvimento rural sustentável, centrado na expansão e fortalecimento da agricultura familiar, que assegure a construção do pleno exercício da cidadania e a melhoria da qualidade de vida da sociedade" (FASER, 1997). Dessa forma, emergiram no conceito de extensão rural termos como participação, desenvolvimento rural sustentável, agricultura familiar e pleno exercício da cidadania, que contrastam com "difundir informações úteis e práticas" e "encorajar a aplicação das mesmas", que estão vinculadas a um período em que a prioridade era o que foi considerada modernização da agricultura. Observa-se, assim, uma proposta de mudança das ações dos extensionistas, que deixariam de priorizar a difusão tecnológica para terem uma orientação pedagógica dialógica na ação. O estímulo à organização autônoma dos produtores também passaria a ser prioridade. O modelo construtivista passou a ser preconizado em substituição ao modelo difusionista. A atuação dos extensionistas deveria contemplar o assessoramento técnico aos produtores no que concerne às atividades agropecuárias, assim como de catalisação de processos sociais. Rodrigues (1997) afirma que o papel da tecnologia passaria a ser essencial, mas dentro de padrões de equilíbrio energético e social. Assim, o autor caracteriza essa forma de fazer extensão como humanismo crítico. A consolidação da necessidade de se adotar metodologias de extensão participativas consolida-se paulatinamente no Brasil. A Política Nacional de Assistência Técnica e Extensão Rural (PNATER) e o Plano Nacional de Extensão Pesqueira e Aquícola (Plano ATEPA), de 2008, integram uma política de apoio a agricultores e aquicultores familiares, respectivamente. Nessa perspectiva, os extensionistas deveriam desempenhar, pelo uso de metodologias participativas, um papel educativo, privilegiando o potencial endógeno das comunidades, resgatando e fazendo interagir os seus conhecimentos com aqueles do público beneficiário. $O$ assessoramento dos extensionistas às associações, cooperativas e grupos informais de agricultores familiares, pescadores artesanais, quilombolas e indígenas, assim como a sua capacidade de apoiar a construção de redes sociotécnicas integradas por diferentes profissionais para apoiar os empreendimentos econômicos solidários, deveria ser assimilado como uma forma de incubação.

Entretanto, há três fatores limitantes para o desenvolvimento dessa metodologia: 1) O governo federal não possui estruturas de execução nos estados e municípios que, de forma geral, não aderiram às referidas políticas de assistência técnica e extensão rural. 2) A formação proporcionada pelas universidades ainda é conservadora, fundamentada nos princípios do difusionismo, o que representa um fator limitante quando os ex-alunos se tornam extensionistas. Esse fato cria uma expressiva lacuna na implementação de políticas de extensão que priorizam a participação. 3) Governos estaduais e municipais não investem de forma adequada nos serviços de extensão.

Os desafios para a criação de uma nova extensão não são desprezíveis, o que 
requer a implementação de políticas públicas que mobilizem diferentes níveis de governo e instituições de ensino para que se tenha, efetivamente, uma política de extensão integrada e que atue segundo a orientação metodológica construtivista.

\subsection{Características do difusionismo e do construtivismo}

\subsubsection{Difusionismo}

A trajetória da extensão é marcada por um longo período em que o modelo difusionista-inovador foi adotado como única metodologia de ação seja na extensão rural. Atualmente o difusionismo ainda é adotado, seja por representantes de fábricas de insumos, que difundem os modelos tecnológicos que dependem da utilização dos produtos que comercializam, seja por extensionistas de órgãos públicos, que são preparados nas escolas técnicas e universidades para difundirem tecnologia e não têm a formação e a cultura de se dedicarem à análise do entorno ou interesse em conhecer, de forma mais detalhada, como vivem os agricultores familiares e por que eles produzem de determinada forma.

A fundamentação do difusionismo tem como referência a "Teoria da Difusão de Inovações", elaborada por Everett Rogers e publicada em 1962 no livro Diffusion of Innovations. Essa teoria fundamentou a atuação da extensão rural na América Latina com mais ênfase a partir de 1963 e durante toda a década de 1970. Pinto (1998) afirma que na visão de Rogers as mudanças sociais produzem transformações na estrutura e funcionamento de um sistema social e são feitas em três etapas:

1) Invenção, processo de criar ou desenvolver ideias novas.

2) Difusão, processo em que as ideias novas são comunicadas aos membros do sistema social.

3) Consequências: as mudanças que ocorrem dentro do sistema social como resultado da adoção ou rejeição da inovação.

Rogers e Shoemaker (1971), apud Pinto (1998), evidenciam o papel da comunicação no processo de mudança social. Destacam o caráter unidirecional da comunicação, a negação do diálogo: “A comunicação é um processo pelo qual mensagens são transferidas desde uma fonte até o receptor. Os elementos centrais no processo de comunicação são a fonte, a mensagem, os canais e os receptores. $A$ difusão é um tipo especial de comunicação que consiste em estender mensagens, que são as novas ideias(...) Os elementos principais na difusão de novas ideias são: 1) a inovação, 2) que é comunicada por meio de certos canais, 3) num tempo estipulado, 4) entre os membros do sistema social. Uma inovação é uma ideia, uma prática ou um objeto percebido como novo pelo indivíduo".

De acordo com Rogers, um agente de mudança, ou seja, o extensionista, é um profissional que terá que influenciar nas decisões de inovação de acordo com o que ele considera desejável. Além do papel de persuasão da extensão, considera-se a 
sociedade como um sistema homogêneo, sem conflitos, e que a tecnologia é o principal fator para o desenvolvimento rural. Assim, se despreza os processos históricos, os movimentos sociais e o conhecimento dos produtores (Pinto, 1998).

A Figura 1 representa o modelo difusionista. Nesse caso, a difusão de um modelo tecnológico pode seguir os seguintes trajetos: 1) O modelo é gerado no país $A$, adaptado nas estações de pesquisa do país $B$, podendo ser difundido por pesquisadores ou extensionistas. 2) $O$ modelo tecnológico é gerado no país A e produtores, comumente capitalizados, do país B importam o modelo sem adaptá-lo, ajustá-lo, em estações de pesquisa. 3) O modelo tecnológico é gerado nas estações de pesquisa de determinado país e é difundido diretamente pelo pesquisador ou pelo extensionista.

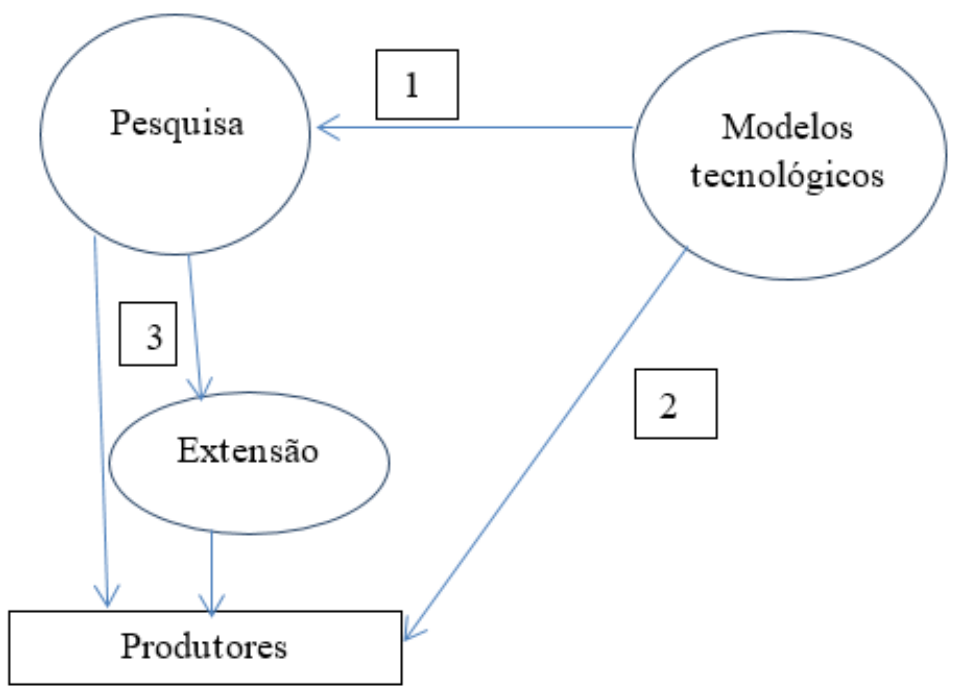

Figura 1. Representação do modelo difusionista

\subsubsection{Construtivismo}

$\mathrm{Na}$ perspectiva construtivista as realidades sociais são apreendidas como construções históricas e cotidianas dos atores individuais e coletivos. O conhecimento não pode ser passado por pacotes tecnológicos, pois nada está pronto e acabado. As respostas emergem da interação entre as pessoas e destas com o meio físico. A palavra construção reenvia aos resultados das elaborações anteriores e aos processos que estão sendo experimentados. A historicidade, ou seja, a análise temporal e espacial das ações humanas se constitui em importante aspecto para os construtivistas, pois "as formas sociais passadas são reproduzidas, apropriadas, substituídas, transformadas, assim como outras são inventadas" (Corcuff, 1995). Não existe apenas uma corrente teórica construtivista. A sociologia da tradução (Callon, 1986) é aquela que melhor se aplica à construção de redes que viabilizarão projetos relacionados à economia solidária.

Fundamentadoem Caporal(1998), pode-seafirmarqueanoçãodedesenvolvimento sustentável supõe o estabelecimento de estilos de produção sustentável que não podem ser alcançados unicamente pela transferência de tecnologias. A necessidade de 
construção de conhecimentos considerando as diferentes condições socioeconômicas dos produtores, a disponibilidade dos fatores de produção, as especificidades dos recursos naturais e as características do mercado determinam que a extensão rural, como um dos instrumentos de fortalecimento das comunidades rurais e litorâneas, adote objetivos, estratégias, metodologias e práticas compatíveis com os requisitos desse novo processo. O que se propõe são ações mais amplas do que transferir tecnologia, pois, segundo o referido autor, inclui a necessidade de uma práxis distinta da convencional e exige-se incorporar aos processos de planejamento participativo os diferentes conhecimentos e estruturas de poder que influenciam a construção do desenvolvimento sustentável. Além disso, sugere-se que a adoção de tecnologia seja entendida como um processo de natureza construtivista, o que implica investigação, aprendizagem e ação, no qual, portanto, se tem que respeitar as pessoas, suas condições objetivas, seus interesses e necessidades. Trata-se de valorização do local, que conduz a um modelo de decisão e ação que contempla o caráter histórico e os aspectos políticos do desenvolvimento rural.

A Figura 2 sugere a trajetória de ações, com base no construtivismo, para a elaboração de projetos de desenvolvimento local. Entende-se o local como um município ou região.

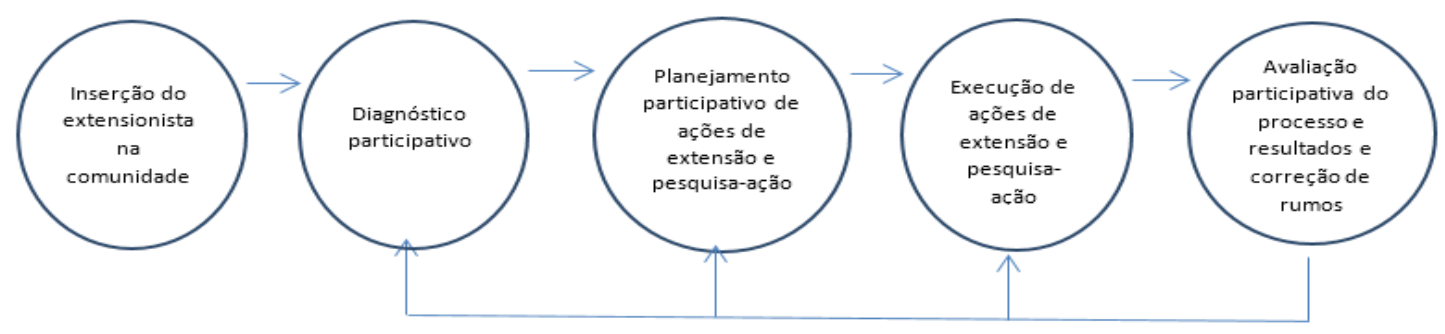

Figura 2. Representação das ações para elaboração de projetos com base no construtivismo

A inserção do extensionista na comunidade é essencial para que estabeleça proximidade com a comunidade e agentes da cadeia produtiva, conheça como os agricultores vivem, as técnicas de produção e por que as adotaram. Trata-se, também, do início do processo de construção de relações de confiança. Caporal (1998) afirma que é de extrema importância que o conhecimento local seja resgatado nesse processo e que seja estabelecida uma integração entre este conhecimento e o conhecimento técnico. Todas as ações do extensionista devem valorizar a participação. O mesmo autor destaca que "...a participação, nesse caso, implica horizontalidade na comunicação e igualdade nas oportunidades de expressar as opiniões e desenvolver as ações, o que está assentado, necessariamente, em uma igualitária relação entre os atores envolvidos". Alerta ainda que "o processo educativo não se trata de uma educação para a adoção de tecnologias transferidas por um agente... mas de um processo que permite desenvolver os conhecimentos e ter acesso a informações suficientes que possibilitem a eleição e a decisão conscientes entre alternativas possíveis".

Além da convivência com os agricultores e observação, pode-se adotar o 
Diagnóstico Rural Participativo (DRP) como forma de reunir informações (Brose, 2001). DRP é um termo empregado para designar um conjunto de ferramentas de trabalho com grupos, utilizadas de forma combinada ou não, para se conhecer a realidade em seus diferentes aspectos: sociais, ambientais, econômicos, governança. Além disso, permite elaborar soluções para os problemas apontados pela comunidade e proporciona o estabelecimento de relações entre o extensionista e produtores, permitindo também, o compartilhamento do pensamento dos participantes.

As etapas da Figura 2 quando realizadas não significa que estão encerradas. Os resultados do DRP podem ser revistos, caso haja necessidade de se fazer correções ou completar informações. Além disso, o planejamento da pesquisa-ação, as ações de extensão e a avaliação do processo e resultados, devem ser feitos de forma contínua, e para cada tema que estiver em questão. Deve-se destacar que a sustentabilidade não é um fenômeno estável, que quando em certo momento alcançada signifique que a atividade será sustentável infinitamente. Ao contrário, deve-se conscientizar que a sustentabilidade deve ser construída cotidianamente e que crises sempre emergirão, sejam elas de caráter econômico, social ou ambiental. Assim, o modelo apresentado na Figura 2 não é um movimento linear, mas circular, pois quanto mais houver planejamento, ação e avaliação, mais condições se terá para construir uma agricultura otimizada e sustentável.

a) Pesquisa-ação

A pesquisa-ação é fundamentada no constante diálogo entre pesquisadores, extensionistas e agricultores familiares. Os seus objetivos quanto às pesquisas que serão realizadas e às inovações técnicas e organizacionais que se esperam obter, são negociados entre os grupos sociais envolvidos. Assim, é incontornável que haja reconhecimento mútuo das competências de cada grupo. Não é uma tarefa fácil negociar com os agricultores as ações que serão realizadas sem que haja portavozes com representatividade. Recomenda-se que se trabalhe com as entidades de representação, sejam associações profissionais ou cooperativas. Quando existe somente uma associação de bairro, há dificuldades de estabelecimento do diálogo, visto que este tipo de entidade representa produtores e não produtores, ou seja, o grupo é heterogêneo quanto aos objetivos que quer alcançar. Lamballe e Castellanet (2003) afirmam que durante a realização da pesquisa-ação o pesquisador se torna produtor e o produtor se torna pesquisador, visto que devem trabalhar em interação, com a valorização dos conhecimentos e práticas mútuos, o que não significa que perderão as suas identidades. Dessa forma, a pesquisa-ação produz mudança social, resolução de problemas concretos e conhecimento científico.

É comum pesquisadores não conhecerem a metodologia das técnicas participativas para elaboração de um plano de trabalho em parceria com os produtores. Assim, o extensionista deve participar disponibilizando o seu conhecimento sobre a realidade local e na mediação do processo.

Para Lamballe e Castellanet (2003) a pesquisa-ação é realizada em três fases: 
- A primeira fase é integrada por duas subfases: diagnóstico da situação e identificação de soluções possíveis. Ao identificar o problema, automaticamente o produtor aponta a solução. O importante é que o diagnóstico e a indicação das soluções sejam realizados pelos produtores. O extensionista e o pesquisador não podem impor as suas percepções, mas devem apresentá-las para o debate, não se omitindo. A Figura 3 simboliza o esforço para que se promova a interação entre os grupos sociais que participam do problema.

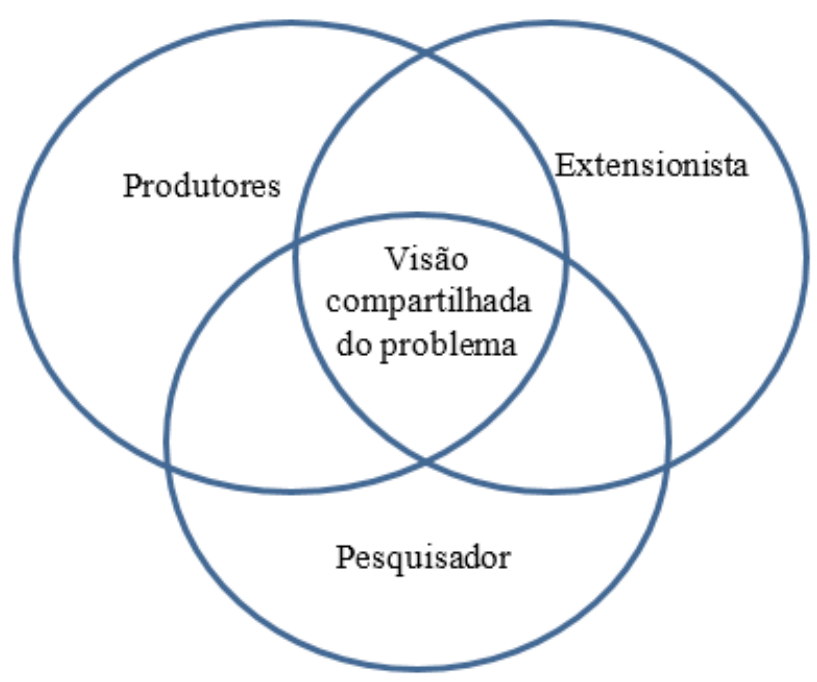

Figura 3. Visão compartilhada de problemas e soluções

A visão compartilhada do problema deve ser a expressão das dificuldades enfrentadas e soluções percebidas pelos agricultores fundamentadas tecnicamente pelos profissionais da extensão e pesquisa.

- A segunda fase é a execução das decisões tomadas. Trata-se da realização da experimentação propriamente dita tendo o cultivo de um produtor como unidade de trabalho. Nesse caso há diversas abordagens técnicas que poderão ser realizadas. Pode-se tratar ainda, de um trabalho na área de socioeconomia, como uma pesquisa de mercado, por exemplo, onde é recomendável que o produtor seja a pessoa que fará as entrevistas com compradores ou possíveis compradores da produção. O pesquisador e o extensionista devem elaborar a metodologia e debatê-la com os produtores, com o objetivo de adequá-la às necessidades que apresentarem. Os trabalhos devem ter uma avaliação contínua, de procedimentos e resultados prévios, que deve ser feita pelo pesquisador e extensionista de forma participativa.

- Avaliação final de resultados

A avaliação final também deve ser participativa e os produtores devem ter informações que fundamentem a tomada de decisões. Trata-se do momento de verificar se o diagnóstico e hipóteses iniciais eram fundamentados. Caso as informações obtidas não sejam satisfatórias, pode-se retomar o trabalho com novas hipóteses.

É de fundamental importância ressaltar que a pesquisa-ação pode ter atividades complementares realizadas em um centro de pesquisa governamental. Esse tipo de 
encaminhamento deve ser muito bem discutido com os produtores para que não haja a impressão de que são realizados trabalhos sem a participação.

b) Caracterização comparativa entre o difusionismo e o construtivismo

As diferenças básicas entre os modelos difusionista e construtivista aplicados à extensão constam no Quadro 1.

\begin{tabular}{|l|l|}
\hline Características do difusionismo & \multicolumn{1}{|c|}{ Características do construtivismo } \\
\hline $\begin{array}{l}\text { Inovação apresentada segundo } \\
\text { suas qualidades }\end{array}$ & Inovação não se impõe por suas qualidades \\
\hline $\begin{array}{l}\text { Modelos técnicos acabados e } \\
\text { completos: pacotes }\end{array}$ & $\begin{array}{l}\text { A inovação é construída pelos atores do processo e } \\
\text { viabilizada por uma rede sociotécnica }\end{array}$ \\
\hline $\begin{array}{l}\text { Único movimento: encontrar os } \\
\text { produtores aptos à adoção da } \\
\text { tecnologia }\end{array}$ & $\begin{array}{l}\text { Valorização do conhecimento do produtor, } \\
\text { identificação dos problemas e elaboração das } \\
\text { soluções }\end{array}$ \\
\hline $\begin{array}{l}\text { Enfoque linear: parte do expert em } \\
\text { direção ao produtor. Transferência } \\
\text { de tecnologia }\end{array}$ & Enfoque participativo. Ação-reflexão-ação \\
\hline O produtor apenas se adapta & $\begin{array}{l}\text { A mudança está centrada nas interações entre } \\
\text { extensionistas e produtores }\end{array}$ \\
\hline $\begin{array}{l}\text { Aumentar a produtividade por } \\
\text { meio de inovações tecnológicas }\end{array}$ & $\begin{array}{l}\text { Modelos criados com base nos recursos locais, } \\
\text { criação de produtos assimilados à territorialidade }\end{array}$ \\
\hline $\begin{array}{l}\text { Conhecimento é gerado em } \\
\text { estações de pesquisa e transferido } \\
\text { aos produtores }\end{array}$ & $\begin{array}{l}\text { Existência de pesquisa-ação. Conhecimento } \\
\text { desenvolvido de forma participativa, com base nas } \\
\text { necessidades e conhecimentos dos produtores, } \\
\text { extensionistas e pesquisadores }\end{array}$ \\
\hline
\end{tabular}

Quadro 1. Características do difusionismo e do construtivismo

Callon (2010) ressalta outros aspectos comparativos entre o difusionismo e o construtivismo, de acordo com o Quadro 2.

\begin{tabular}{|l|l|}
\hline \multicolumn{1}{|c|}{ Difusionismo } & \multicolumn{1}{c|}{ Construtivismo } \\
\hline Atores paralisados & Estimula e libera iniciativas \\
\hline A ideia inicial pode tudo & $\begin{array}{l}\text { A ideia tem que ser processada, } \\
\text { debatida, enriquecida }\end{array}$ \\
\hline Todos dependem das ideias de poucos & A ideia é construída por diferentes atores \\
\hline $\begin{array}{l}\text { Não há margem de manobra para o } \\
\text { inovador }\end{array}$ & $\begin{array}{l}\text { Inovador faz e desfaz alianças. Espaço } \\
\text { de escolhas estratégicas }\end{array}$ \\
\hline $\begin{array}{l}\text { Tudo repousa sobre o inventor e suas } \\
\text { ideias }\end{array}$ & Construção de vínculos e relações \\
\hline Ideia acabada & $\begin{array}{l}\text { Redes sociotécnicas: inovação é } \\
\text { resultado de um processo coletivo }\end{array}$ \\
\hline $\begin{array}{l}\text { Rota e destino são dadas na origem por } \\
\text { um expert }\end{array}$ & $\begin{array}{l}\text { Ninguém conhece o fim da viagem, mas } \\
\text { vamos viajar juntos }\end{array}$ \\
\hline
\end{tabular}

Quadro 2. Características do difusionismo e do construtivismo

Callon (2010)

É importante destacar que no construtivismo uma técnica, ideia ou projeto não se impõem segundo as suas qualidades; mas uma técnica, ideia ou projeto são construídos para atender as necessidades das pessoas que estão envolvidas no problema. Assim, 
evidencia-se que é necessário haver uma rede integrada por diferentes atores, com diferentes competências, para viabilizar a proposta, que deve emergir dos processos participativos.

\subsubsection{Participação}

A participação dos produtores nos processos de elaboração e execução de projetos pode se dar por meio de associações profissionais, associações de bairro e cooperativas. A participação individual, sem vínculo com um empreendimento econômico solidário ou entidade de representação, pode reduzir a legitimidade do participante, dificultando o seu reconhecimento pelos demais atores.

Existem diferentes níveis de participação dos agricultores na elaboração de projetos de desenvolvimento, seja no marco teórico difusionista ou construtivista. É importante evidenciar que no difusionismo as relações são verticais e no construtivismo horizontais. Assim, considerando a Figura 4, elaborada por Beuret (2006), pode-se identificar ações vinculadas à difusão como aquelas que estão sob a linha pontilhada: comunicação, informação e consulta. Aquelas que estão sobre a referida linha, vinculam-se ao construtivismo.

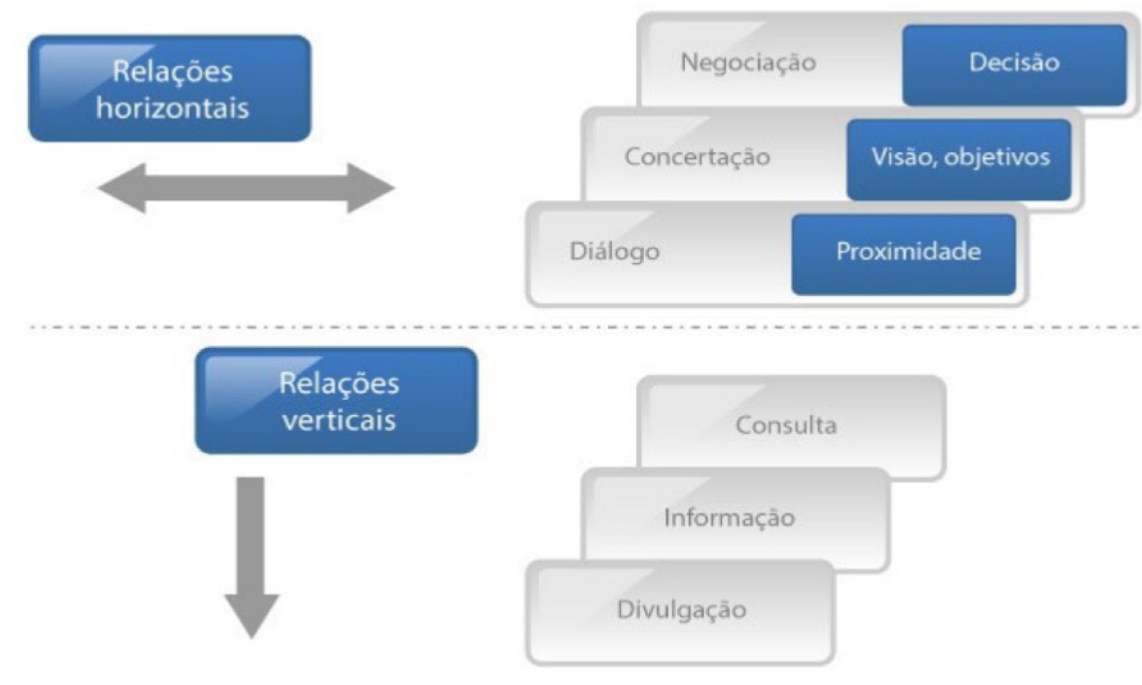

Figura 4. Representação dos níveis de participação dos produtores nos projetos de desenvolvimento (Beuret, 2006)

Segue detalhamento de cada um dos níveis de participação apresentados com exemplificações adaptadas à agricultura.

Divulgação: trata-se de fazer uma comunicação pessoal aos agricultores ou por meio(s) de comunicação de massa, caracterizando-se por ser de fluxo único. Normalmente o objetivo desse tipo de ação é obter a adesão do público. Como exemplo pode-se citar a comunicação de órgão governamental de que haverá uma feira de produtos da agricultura familiar. Exemplo: Os agricultores interessados em participar da feira oferecerão seus produtos nos pontos de venda pré-estabelecidos pelo governo, disponibilizando, no mínimo, 5 toneladas de produto. A participação dos 
agricultores após uma comunicação como esta limita-se a aderir à campanha.

Informação: a informação ainda é uma ação de fluxo único que, normalmente, parte dos gestores públicos em direção ao público-alvo. Informa-se sobre as decisões do governo com o objetivo de fornecer elementos de compreensão de uma decisão ou projeto previamente elaborado. A informação permite ao público construir uma opinião e tomar uma decisão frente ao que se propõe. Exemplo: determinado governo informa aos agricultores, por meio de reuniões conduzidas por extensionistas, que possui uma linha de financiamento para associações ou cooperativas realizarem investimentos. Para isso, devem possuir um mínimo de 12 associados, arcar com $30 \%$ do valor total do projeto e realizar um plano de negócios que comprove a viabilidade de sua adesão. Considerando que existe a compreensão da mensagem, os agricultores formarão opinião e decidirão se participam ou não de acordo com as condições objetivas que possuem, considerando: a entidade possui um mínimo de 12 associados interessados no projeto? Há recursos para garantir a contrapartida de $30 \%$ do valor total do projeto? Há maturidade profissional para elaborar um plano de negócios ou será necessário remunerar um profissional para fazê-lo? Enfim, cabe aos associados apenas decidir se participarão ou não, sem que possam realizar mudanças no projeto governamental apresentado.

Consulta: trata-se de coleta de opiniões realizada, comumente, por um órgão de governo por meio de um extensionista. Pode-se criar algum debate sobre temas específicos, mas não há qualquer garantia de que os agricultores participarão das decisões que serão fundamentadas nas respostas da consulta. $\mathrm{O}$ debate pode ser um fator de estímulo à participação dos envolvidos, mas quando ocorre a sua limitação, trata-se de uma decisão previamente tomada pelo fato de o agente do governo optar por se proteger de eventuais demandas que poderão ser apresentadas.

Apesar disso, na consulta há mais avanços em relação à participação comparativamente às situações anteriores: comunicação e informação. Exemplo: determinado governo, por meio de extensionistas, decide diagnosticar a agroecologia em determinada região, as práticas adotadas, os problemas enfrentados segundo os agricultores etc. Porém, não é assegurada a participação no projeto que apontará soluções. A consulta pode ser feita com a aplicação de questionários ou por meio de reuniões, utilizando-se ferramentas do Diagnóstico Rural Participativo. Quando feita em atividades grupais podem ocorrer debates, desde que haja animação. Trata-se de uma ação que ainda se situa no campo das relações verticais por ser estabelecido que o interesse e decisão estão concentrados no agente do governo.

Diálogo: o diálogo é a primeira etapa na escala das relações horizontais. Tratase de uma forma de estabelecer proximidade entre os diferentes atores que estarão envolvidos no projeto de desenvolvimento. As pessoas começam a se conhecer, a se compreender de forma mútua em relação à metodologia de elaboração e execução do projeto, assim como de seus objetivos. É importante que para o estabelecimento do diálogo, o que representa o início da elaboração de um projeto coletivo, estejam 
presentes em reuniões os agricultores, extensionistas, pesquisadores, representantes de órgãos ambientais, membros de agências de financiamento, agentes de governo. Exemplo: diferentes atores que atuam direta ou indiretamente na agricultura familiar são convidados para debaterem os problemas regionais concernentes às atividades e possíveis soluções. Não se deve excluir nenhum ator social.

Além desse evento, o diálogo também deve ser estimulado no seio das associações e cooperativas, com reuniões frequentes para debater questões relacionadas às atividades. Nesses eventos, antes dos debates, podem ser realizadas palestras com extensionistas e pesquisadores sobre temas de escolha dos agricultores. Pode-se organizar também a apresentação de resultados obtidos por um agricultor, a fim de se debater o sistema adotado. O diálogo é uma etapa importante para construir a coesão social necessária à elaboração e execução do projeto coletivo. Trata-se de um movimento de mudança, pois se migra das ações individuais para uma ação coletiva.

Concertação: a concertação representa o entendimento entre os diferentes atores em relação às bases do projeto. Os agentes governamentais devem estar cientes que deverão compartilhar o poder de decisão para que haja efetivamente um processo de concertação. Mermet (1998), apud Beuret (2006), afirma que a concertação é mais avançada que uma consulta, pelo fato de representar a adaptação das decisões às necessidades dos atores, após um esforço para ajustar os interesses de cada um. Em relação à etapa seguinte, a negociação, a concertação é menos avançada no que concerne à participação, pelo fato de não representar ainda a tomada de decisão em relação a um acordo comum, de não representar ainda um compromisso. O objetivo dessa etapa é construir uma visão comum do problema. Exemplo: em um processo de concertação com a presença de agricultores, extensionistas, pesquisadores etc, debate-se quais práticas deverão ser recomendadas, considerando-se os diferentes sistemas de cultivo existentes na região, ou seja, busca-se construir um modelo que seja adequado à maioria dos agricultores, que tenha viabilidade econômica, reduzido impacto ambiental e que seja passível de ser financiado. Assim, inicia-se um processo em que os pesquisadores irão estudar os modelos existentes em seus diferentes aspectos diretamente nas unidades de produção, com apoio e informações dos agricultores. Posteriormente, haverá a apresentação de resultados. Independente da tomada de decisão quanto ao modelo mais adequado, está em curso um processo que permite a construção de visões e objetivos, que serão as bases do projeto. Trata-se de uma etapa de elaboração na escala de participação, considerando-se as relações horizontais.

Negociação: a negociação representa a tomada de decisão entre os atores. Dupont (1994), apud Beuret (2006), define a negociação como "uma atividade que coloca em interação vários atores que, confrontados ao mesmo tempo com as divergências e interdependências, escolhem buscar voluntariamente uma solução mútua aceitável'. Exemplo: considerando os diferentes sistemas de cultivo em determinada região, havia aqueles de produção orgânica. Alguns ainda praticavam a agricultura convencional. 
Considerando a demanda dos consumidores locais, a associação decidiu implantar uma Organização de Controle Social ${ }^{1}$ com produtos comercializados em duas feiras semanais de produtores. A decisão foi tomada e um conjunto de ações definido: acompanhamento de algumas propriedades por pesquisadores e extensionistas para se compreender melhor os aspectos econômicos e ambientais do sistema; reuniões mensais em associações de produtores com apresentação e debate sobre as operações técnicas realizadas e os resultados obtidos; cursos para produtores e extensionistas sobre as técnicas do modelo, considerando os dados de pesquisas realizadas nas propriedades. Essa etapa é a mais elevada no processo de participação das relações horizontais, visto que um modelo de criação foi escolhido após um processo de concertação.

\subsection{Economias de Grandeza}

As pessoas estão inseridas nas organizações que integram em situações que são ao mesmo tempo cooperativas e conflituais, ou seja, de interesses divergentes em relação a outras pessoas. Cooperação não faz, necessariamente, referência a um acordo amigável, posto que não é a amizade o elemento indispensável à aparição da cooperação para a prática da economia solidária, mas a interdependência mútua e a reciprocidade. Não é possível obter a coordenação entre atores que permanecem cada qual imerso apenas na lógica de ação de seu respectivo mundo, posto que diferentes mundos representam diferentes grandezas ou sistemas de equivalência (Andrade et al., 2001).

Para que existam trocas e coordenação é preciso que sejam estabelecidas convenções entre as pessoas que integram uma associação ou cooperativa ou entre representantes destas entidades e o poder público, empresas ou consumidores, por exemplo. Trata-se de acordos formais ou informais sem os quais nenhuma forma de troca seria possível na sociedade, mesmo as pontuais. A economia das convenções é uma corrente da economia que coloca no centro da sua análise a construção de acordos e trocas. Um exemplo clássico de estudos realizados pelos convencionalistas são as relações estabelecidas no mundo do trabalho entre patrões e empregados. Neste caso, geralmente, há uma relação conflituosa por haver divergência de interesses, mas também há cooperação. Trata-se, assim, de uma convenção de trabalho onde são resolvidos os conflitos (Amblard et al., 2005).

O sociólogo Luc Boltanski e o economista Laurent Thévenot fundamentaram-se na ideia de que a construção da sociedade não pode ser justificada somente pelas relações econômicas ditadas pelo mercado ou, por outro lado, unicamente pelas regras que se sedimentam ao longo do tempo e integram a cultura, hábitos e o saber

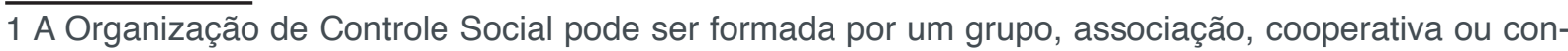
sórcio, com ou sem personalidade jurídica, de agricultores familiares. Mas, para que a Organização seja reconhecida pela sociedade e ganhe credibilidade, é preciso que entre os participantes exista uma relação de organização, comprometimento e confiança.

http://www.planetaorganico.com.br/arquivos/CONTROLE_SOCIAL.pdf 
comum de determinado grupo. Assim, sugeriram rejeitar essas justificativas que se opõem por considerá-las superficiais e propuseram uma teoria que se apoia nos acordos justificados e legitimados entre os integrantes de uma sociedade. Essa teoria foi denominada economias de grandeza e integra o arcabouço teórico da economia das convenções. Amblard et al. (2005) afirmam que a preocupação central dos convencionalistas em geral e em particular dos autores das economias de grandeza é a reflexão sobre a produção dos acordos, a realização da coordenação entre pessoas.

Uma cooperativa ou associação de agricultores é um espaço de estabelecimento de regras entre seus integrantes para a realização de atividades coletivas, assim como de negociações com fornecedores e compradores. Assim, as relações existentes não podem ter sua compreensão reduzida aos aspectos puramente sociais ou econômicos. A teoria das economias de grandeza é apresentada para que se possa compreender as lógicas de ação das pessoas e facilitar a construção de acordos. Boltanski e Thévenot (1991) afirmam que as relações, os acordos ou os desacordos, fundamentam-se em grandezas, que são sistemas de equivalência regidos pela coerência de princípios e ativados por cada pessoa para justificar as suas posições e ações. Enfim, uma situação ou fato podem ser considerados grandes por um indivíduo e pequenos por outro. Dessa forma, grandeza refere-se à equivalência de princípios, sendo que grande significa o que é relevante, o que possui uma maior representação. Utilizando-se as grandezas definidas pelos autores, identificam-se os valores que definem as posições das pessoas nas controvérsias e conflitos.

Boltanski e Thévenot (1991) definiram seis sistemas de equivalência, que denominaram mundos: Inspiração, Doméstico, Opinião, Cívico, Mercantil e Industrial. Os mundos são caracterizados da seguinte forma:

Mundo Inspiração: os valores do mundo inspiração estão associados à genialidade, à criação. Para Corcuff (1995), esse mundo estabelece uma ligação imediata entre pessoas e uma totalidade. Como exemplos podem ser citados Deus para os místicos ou a arte para os artistas. Para Amblard et al. (2005) «o homem criativo e sua equipe em uma agência de publicidade, o pesquisador e seus colegas de laboratório, assim como o arquiteto e seus assistentes, são pessoas fortemente submetidas ao mundo da inspiração». Pode haver controvérsias dentro de um mesmo mundo, como ciência x religião, por exemplo, visto que para os cientistas é preciso que haja comprovação científica dos fatos, enquanto para os religiosos basta a fé para que o fato exista.

Mundo Doméstico: este mundo compreende três aspectos simultaneamente imbricados: um é temporal, devido à fidelidade das pessoas aos costumes. Outro é espacial, de familiaridade e um terceiro é hierárquico, de autoridade. A confiança para a realização de práticas solidárias é uma característica desse mundo. As relações entre os seres humanos são de longo prazo e fundamentam-se na familiaridade (Boltanski e Thévenot, 1991). Assim, segundo Amblard et al. (2005), as figuras de referência são aquelas da família, da tradição, dos ancestrais. A noção de patrimônio é chave, 
pois ela designa uma totalidade constituída de bens apropriados com vistas ao seu uso e transmissão. As relações estabelecidas motivadas por fatores socioculturais em determinado território estão inseridas nesse mundo.

Mundo Opinião: para a grandeza opinião, somente a consagração pública importa. Não interessa o espírito criador do mundo de inspiração ou o respeito às tradições do mundo doméstico. No primeiro caso, há o risco de haver isolamento e não ter reconhecimento público. No segundo caso, a limitação da ação a regras impediria o alcance da celebridade. Amblard et al. (2005) caracteriza como integrantes desse mundo desejos como ter reputação reconhecida, ser considerado, ter um julgamento positivo por expressivo número de pessoas, ter sucesso.

As ações de promoção estabelecidas com o objetivo de ganhar aliados, como consumidores conscientes e o poder público em apoio à economia solidária pela promoção das suas qualidades socioeconômicas e ambientais estão inseridas neste mundo.

Mundo Cívico: no mundo cívico prevalece o interesse coletivo, sempre acima do interesse particular. As pessoas se mobilizam em torno de noções como equidade, liberdade e solidariedade. Há uma grande valorização dos direitos de cada um e dos representantes legais. O cooperativismo é uma forma de organização que se enquadra nesse tipo de grandeza, com ênfase no coletivo e na solidariedade. $O$ interesse coletivo não significa a soma dos interesses individuais, mas um interesse superior comum (Amblard et al., 2005). As relações estabelecidas para a definição de práticas de agroecologia ou de um modelo de criação de peixes para uma coletividade estão inseridas nessa grandeza.

Mundo Mercantil: este mundo é fundamentado no princípio da concorrência, sendo os preços a referência universal do valor dos objetos. É o mundo dos interesses particulares e as pessoas estão em relação por ocasião dos negócios, que são caracterizados pelo oportunismo. A ligação social é fundamentada somente pelas trocas, que são feitas supostamente em benefício de todos, para contribuir com o bem comum. Esse mundo é caracterizado pelo concorrencial, pela captação de clientela, obtenção dos melhores preços e do máximo proveito nas transações. Para essa grandeza, o mundo doméstico não é suficiente pelo fato de as relações domésticas impedirem a obtenção de sucesso com o aproveitamento de todas as oportunidades comerciais (Amblard et al., 2005). As transações comerciais estão inseridas neste mundo.

Mundo Industrial: Boltanski e Thévenot (1991) afirmam que as características do mundo industrial não devem ser confundidas com as do mundo mercantil, apesar de ambas constituírem coordenações de ordem econômica. No mundo industrial, o desempenho técnico, a aplicação dosconhecimentos gerados pela ciência fundamentam a busca pela eficácia. Amblard et al. (2005) afirmam que investir em uma máquina ou na formação de um operador que vai conduzi-la, assim como medir a produtividade utilizando-se de instrumentos desenvolvidos cientificamente, são características 
típicas do mundo industrial. Para esses autores, uma empresa fortemente equipada, moderna na sua forma de produzir, com profissionais que dominam integralmente a tecnologia, constituem essa grandeza. A produção de commodities agrícolas está inserida nesse mundo.

O Quadro 3 apresenta uma síntese da caracterização das ordens de grandeza.

\begin{tabular}{|l|l|l|l|l|l|l|}
\hline & \multicolumn{1}{|c|}{ Inspiração } & \multicolumn{1}{|c|}{ Doméstico } & \multicolumn{1}{c|}{ Opinião } & \multicolumn{1}{c|}{ Cívico } & \multicolumn{1}{c|}{ Mercantil } & \multicolumn{1}{|c|}{ Industrial } \\
\hline $\begin{array}{l}\text { Valores de } \\
\text { referência }\end{array}$ & $\begin{array}{l}\text { Inspiração, } \\
\text { criação, } \\
\text { imaginação }\end{array}$ & $\begin{array}{l}\text { Tradição, } \\
\text { família, } \\
\text { hierarquia }\end{array}$ & $\begin{array}{l}\text { Reputação, } \\
\text { fama }\end{array}$ & $\begin{array}{l}\text { Coletividade, } \\
\text { democracia, } \\
\text { vontade geral }\end{array}$ & $\begin{array}{l}\text { Concorrência, } \\
\text { rivalidade }\end{array}$ & Eficácia \\
\hline $\begin{array}{l}\text { Características } \\
\text { valorizadas }\end{array}$ & $\begin{array}{l}\text { Espontaneidade, } \\
\text { emoção }\end{array}$ & $\begin{array}{l}\text { Fidelidade, } \\
\text { discrição, } \\
\text { benevolência, } \\
\text { decoro }\end{array}$ & $\begin{array}{l}\text { Celebridade, } \\
\text { visibilidade, } \\
\text { sucesso, moda }\end{array}$ & $\begin{array}{l}\text { Representatividade, } \\
\text { unidade, legalidade }\end{array}$ & $\begin{array}{l}\text { Ganho, valor, } \\
\text { lucro }\end{array}$ & $\begin{array}{l}\text { Funcionalidade, } \\
\text { validação } \\
\text { científica, } \\
\text { performance }\end{array}$ \\
\hline $\begin{array}{l}\text { Características } \\
\text { desvalorizadas }\end{array}$ & Hábito, rotina & $\begin{array}{l}\text { Novidade, } \\
\text { grosseria, } \\
\text { traição }\end{array}$ & $\begin{array}{l}\text { Indiferença, } \\
\text { obsolescência }\end{array}$ & $\begin{array}{l}\text { Divisão, } \\
\text { individualismo, o } \\
\text { arbitrário, o ilegal }\end{array}$ & $\begin{array}{l}\text { Derrota, } \\
\text { falta de } \\
\text { competitividade }\end{array}$ & $\begin{array}{l}\text { Improdutivo, } \\
\text { ineficaz }\end{array}$ \\
\hline $\begin{array}{l}\text { Sujeitos } \\
\text { valorizados }\end{array}$ & $\begin{array}{l}\text { Artista, o gênio, o } \\
\text { iluminado }\end{array}$ & $\begin{array}{l}\text { O pai, o rei, o } \\
\text { patrão, o pajé }\end{array}$ & $\begin{array}{l}\text { Vedete, } \\
\text { audiência }\end{array}$ & $\begin{array}{l}\text { O representante, o } \\
\text { eleito }\end{array}$ & $\begin{array}{l}\text { Vendedor, o } \\
\text { homem de } \\
\text { negócios }\end{array}$ & $\begin{array}{l}\text { O expert, o } \\
\text { profissional, o } \\
\text { operador }\end{array}$ \\
\hline $\begin{array}{l}\text { Práticas } \\
\text { harmoniosas }\end{array}$ & $\begin{array}{l}\text { Criação a partir } \\
\text { de uma folha } \\
\text { branca, liberdade } \\
\text { do espírito }\end{array}$ & $\begin{array}{l}\text { Cerimônias } \\
\text { familiares, } \\
\text { recepçães }\end{array}$ & $\begin{array}{l}\text { Olhar dos } \\
\text { outros sobre } \\
\text { um evento }\end{array}$ & $\begin{array}{l}\text { A eleição, a } \\
\text { manifestação }\end{array}$ & $\begin{array}{l}\text { O mercado, a } \\
\text { conclusão de } \\
\text { um negócio }\end{array}$ & $\begin{array}{l}\text { O teste, a } \\
\text { realização }\end{array}$ \\
\hline
\end{tabular}

Quadro 3. Caracterização das ordens de grandeza

Fonte: Boltanski e Thévenot (1991)

Nas organizações de produtores podem emergir conflitos entre representantes do mesmo mundo ou de mundos diferentes, o que é mais comum. Há situações em que participantes atuam para que haja a priorização das relações mercantis em detrimento das relações fundamentadas na tradição, ou seja, do mundo doméstico, ou nas ações coletivas como os mutirões, nesse caso cívicas. É importante, porém, que haja no grupo um equilíbrio entre as ações de cada ordem de grandeza. Os resultados econômicos de um empreendimento econômico solidário serão consequência das relações sociais. Mesmo o mercado é resultado das relações entre pessoas. Porém, como verificado na Figura 5 as grandezas cívica, doméstica e mercantil devem ser necessariamente mobilizadas e colocadas em interação, para que determinada atividade esteja inserida em um projeto de economia solidária. Dessa forma, o empreendimento gerará renda e se fundamentará na reciprocidade e na valorização dos conhecimentos dos seus integrantes. 


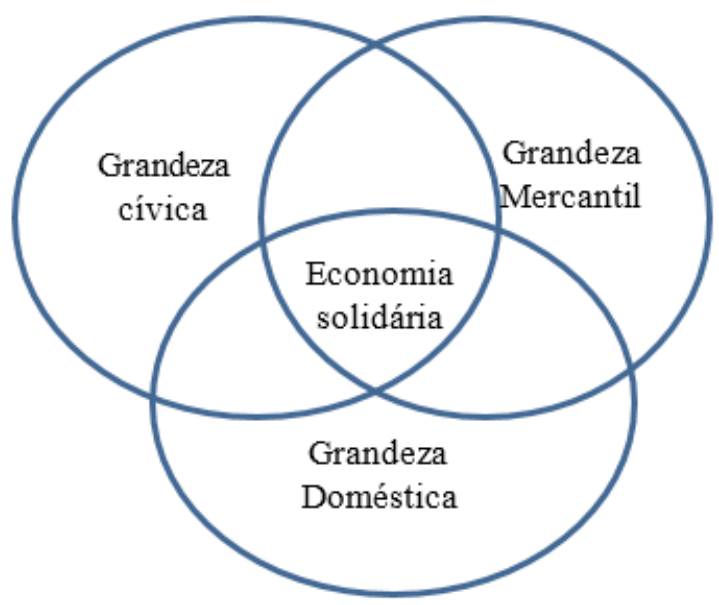

Figura 5. Representação das ordens de grandeza relacionadas com a economia solidária

O conflito mais comum entre pessoas que representam lógicas de ação diferentes na economia solidária ocorre entre os mundos mercantil e cívico. É comum a incompreensão de que a economia solidária é resultado de relações de reciprocidade entre integrantes do grupo e destes com clientes e poder público para a construção de uma economia que não se fundamenta na troca mercantil. A formação quanto aos valores e princípios da economia solidária pode promover o acordo entre esses mundos. Porém, outros conflitos podem ocorrer, como a crítica do mundo mercantil ao mundo doméstico: «a tradição não gera renda». O acordo entre esses mundos pode ser construído no turismo de base comunitária, forma de organização em que a contribuição financeira dos visitantes fortalece a cultura local. No Quadro 4 consta uma relação de atividades concernentes a um grupo de economia solidária relacionadas às economias de grandeza. O planejamento e execução de cada uma pode ocorrer como acordo após a existência de controvérsias.

\begin{tabular}{|l|c|l|}
\hline \multicolumn{1}{|c|}{ Atividade } & $\begin{array}{c}\text { Ordem de } \\
\text { Grandeza }\end{array}$ & \multicolumn{1}{|c|}{ Informação complementar } \\
\hline $\begin{array}{l}\text { Participação dos integrantes } \\
\text { do EES em pesquisa-ação } \\
\text { para gerar informações e } \\
\text { possibilitar inovações }\end{array}$ & Inspiração & $\begin{array}{l}\text { A pesquisa científica é integrante do mundo da } \\
\text { inspiração, mas se outros agricultores familiares } \\
\text { participam/ajudam, mobiliza-se também a } \\
\text { grandeza cívica }\end{array}$ \\
\hline $\begin{array}{l}\text { Gestão do EES com a } \\
\text { valorização do conhecimento } \\
\text { local, da tradição. Influência } \\
\text { das lideranças mais velhas. }\end{array}$ & Doméstica & Atividade relacionada à tradição, à família \\
\hline $\begin{array}{l}\text { Apresentação dos resultados } \\
\text { da associação ou cooperativa } \\
\text { para a imprensa }\end{array}$ & Opinião & $\begin{array}{l}\text { Ações que buscam a conquista da opinião pública } \\
\text { são do mundo opinião }\end{array}$ \\
\hline $\begin{array}{l}\text { Participação de atividades } \\
\text { em mutirão ou reuniões na } \\
\text { associação ou cooperativa } \\
\text { com o objetivo de definir } \\
\text { regras para o fundo rotativo } \\
\text { da entidade }\end{array}$ & Cívica & $\begin{array}{l}\text { O mutirão de despesca, por exemplo, se integrado } \\
\text { por aquicultores também representa a ordem de } \\
\text { grandeza cívica. Mutirões para plantio ou colheita } \\
\text { seguem a mesma lógica. }\end{array}$ \\
\hline
\end{tabular}




\begin{tabular}{|l|l|l|}
\hline Comercialização da produção & Mercantil & $\begin{array}{l}\text { As relações de mercado são do mundo mercantil, } \\
\text { mas se realizadas coletivamente, a ação } \\
\text { incorpora aspectos da grandeza cívica }\end{array}$ \\
\hline $\begin{array}{l}\text { Teste de um equipamento } \\
\text { para a associação ou } \\
\text { cooperativa para melhorar a } \\
\text { eficiência da gestão }\end{array}$ & Industrial & $\begin{array}{l}\text { A operacionalização da ciência com o teste de um } \\
\text { equipamento ou técnica é um aspecto do mundo } \\
\text { industrial }\end{array}$ \\
\hline
\end{tabular}

Quadro 4. Atividades de um empreendimento econômico solidário e suas respectivas ordens de grandeza

As ações dos integrantes da associação ou cooperativa como representadas no Quadro 4 mostram que há um esforço para que a atividade seja sustentável, pois há a mobilização de diferentes ordens de grandeza que contemplam a pesquisa, o mercado, a cooperação, a valorização da tradição, a sensibilização da opinião pública, o aperfeiçoamento técnico. Nem sempre os integrantes do empreendimento econômico solidário têm compreensão ou aptidão para realizar todas as articulações necessárias para operacionalizar as ações descritas ou mesmo inexiste a cooperação necessária entre pessoas por terem suas lógicas pautadas pelas diferentes ordens de grandeza, podendo, inclusive, haver conflitos. Assim, o extensionista deve assessorar os grupos, colocar em relação atores sociais dos diferentes mundos a fim de integrar a dinâmica local por meio da convergência de interesses, atuar na divulgação dos resultados alcançados e das atividades coletivas em reuniões das organizações dos produtores, por exemplo.

\subsection{Sociologia da tradução}

Asociologia da tradução também é denominada sociologia das redes sociotécnicas ou sociologia da inovação. O seu nascimento se deu do estudo das condições de produção da ciência e da tecnologia realizados principalmente pelos franceses Michel Callon e Bruno Latour, mas atualmente é aplicada para a compreensão ou promoção de processos de inovações nas empresas e organizações (Bernoux, 2004). A sua utilização como referencial teórico para o desenvolvimento da agricultura fundamentase na premissa de que a atividade somente se viabiliza se for resultado de uma rede sociotécnica, integrada por diferentes atores em cooperação, sendo eles os agricultores, pesquisadores, extensionistas, representantes de agências de financiamento, fornecedores, consumidores etc. A inovação é comumente apresentada segundo o difusionismo. Neste modelo, um pacote tecnológico tem a função de encontrar um produtor ou grupo de produtores que o adote. Na trajetória clássica das informações no difusionismo as técnicas são desenvolvidas por um pesquisador e são difundidas pelo extensionista para os produtores. Assim, apenas uma parte dos beneficiários está apta à nova tecnologia, visto que não é considerada as características e necessidades do conjunto de produtores. Trata-se do modelo vertical descendente. Na tradução, a inovação somente se viabiliza como resultado da construção de uma rede, ou seja, 
em um processo construtivista. Bernoux (2004) afirma que o modelo da tradução é mais trabalhoso de ser viabilizado, mas certamente é o único eficaz, considerando os resultados que serão produzidos para a totalidade dos produtores.

Para o entendimento do mecanismo da construção de redes sociotécnicas é necessário o conhecimento de alguns conceitos-chave como rede sociotécnica; tradução; controvérsia; fato e rede; simetria, que foram relacionados tendo como base as publicações dos sociólogos da inovação.

Rede sociotécnica

A rede sociotécnica é definida como uma organização integrada pelas entidades humanas e não humanas, individuais ou coletivas, definidas por seus papéis, objetivos, identidades e programas, colocadas em intermediação uns com os outros (Callon, 1999). Para Bernoux (2004) o coração da sociologia da tradução é constituído pela ideia de que uma inovação, seja técnica ou organizacional, não tem força necessária para se impor quando inexiste uma rede sociotécnica que a viabilize. Assim, um projeto como a organização de agricultores em associação ou cooperativa, por exemplo, aparentemente é bom. Porém, ele se tornará efetivamente bom se uma rede sociotécnica viabilizá-lo, pois não se imporá pelas suas qualidades próprias. São os integrantes da rede atuando em cooperação, de forma alinhada, que farão com que a ideia se torne boa, que o projeto seja bom. Latour (2000) afirma que a rede será tão forte quanto o seu elo mais fraco. O desafio, portanto, é colocar os atores sociais, heterogêneos, em relação para construir a rede, visto que cada um deles tem um objetivo particular e uma lógica de ação específica. Assim, é necessário que essas lógicas de ação sejam compreendidas, que haja o entendimento de que somente o trabalho em rede pode viabilizar o objetivo de cada um. Quando um ator alcança o seu objetivo, ele viabiliza que outro ator também alcance o seu objetivo. A construção da rede sociotécnica está condicionada à realização de traduções.

É importante ressaltar a diferença existente entre cadeia produtiva e rede sociotécnica. Cadeia produtiva é considerada como o itinerário dos produtos e informações concernentes à determinada atividade, que contribuem desde a formação até a disponibilização do produto final (Davis e Goldberg, 1957). Assim, a cadeia produtiva é integrada pelos agentes econômicos, consumidores e por aqueles que geram e disponibilizam conhecimento. Para Batalha (2005), com a compreensão do funcionamento da cadeia podem surgir opções de intervenções, públicas e privadas, capazes de aperfeiçoar os mecanismos de geração de valor. Amblard et al. (2005) afirmam que o conceito de rede sociotécnica, originário da sociologia da tradução, pressupõe que os atores envolvidos em determinada atividade econômica atuem de forma coordenada para alcançarem objetivos que integram um quadro de interesse comum. Esse conceito se diferencia daquele de cadeia produtiva, originário da economia, que não propõe o aprofundamento do conhecimento das relações estabelecidas entre os diferentes agentes que integram a cadeia. Segundo Bernoux 
(2004), é impossível compreender os fatores responsáveis pelos resultados econômicos de uma atividade excluindo-se da análise as relações entre os atores e suas influências recíprocas. Além da necessidade da existência de traduções e de compromisso, o estabelecimento de relações de confiança entre os agentes da cadeia produtiva é de fundamental importância para a construção de redes sociotécnicas. Para Fournier et al. (2005), a garantia de reciprocidade nas trocas no seio da cadeia proporciona a redução dos custos de cobertura de risco, favorecendo a realização de transações a preços inferiores àqueles do mercado. Além das relações verticais estabelecidas por fornecedores e clientes, típicas da cadeia produtiva, na rede sociotécnica há relações horizontais entre os agentes. Estas podem ser representadas por acordos formais e informais de cooperação, adequação dos produtos às necessidades dos clientes e trocas de informações e saberes.

\section{Tradução}

Para os sociólogos da tradução, traduzir não tem o sentido que essa palavra possui na linguagem corrente. Não se trata de passar um texto de um idioma para outro. Callon (1999) exemplifica o conceito de tradução. Em uma situação emergente, o ator $A$, engajado na produção de conhecimentos porta um enunciado não inteligível para $o$ ator $B$. Se $A$ transmite a $B$ os seus conhecimentos em forma de enunciado codificados, esse último não está dotado de competências necessárias para a sua compreensão por ter uma lógica de ação diferente do primeiro. B não pode ver utilidade nos conhecimentos de $A$, a não ser que este se lance em uma tarefa de estabelecer um elo de inteligibilidade com $B$ e crie um cenário de interesse comum em que se estabelecem compromissos a partir da conciliação de propósitos. A tradução é um processo que proporciona a convergência de interesses. Assim, não se trata de convencer o outro. Dessa forma, A seria o tradutor de B. No início da tradução, as posições entre os atores envolvidos são divergentes, mas ao seu fim um discurso as unifica e as coloca em relação de forma inteligível possibilitando compreender as vozes falando em uníssono e se compreendendo mutuamente. A tradução é um processo antes de ser um resultado, que permite estabelecer uma equivalência constantemente renegociada entre o produtor do conhecimento e o utilizador em potencial. Ela passa frequentemente pela construção de novos atores e interesses, com base no deslocamento de posições desses mesmos atores, na medida em que avançam as negociações e a convergência.

Beuret (2006) afirma que o perfil do tradutor é de fundamental importância para que as traduções sejam realizadas. Para o autor, de forma geral, o tradutor deve saber construir um clima de cooperação entre os atores sociais, ter capacidade de ouvir, favorecer as proximidades e estabelecer parcerias, dialogar com integrantes do poder público e ter criatividade, formação técnica e engajamento pessoal.

O poder público deve assumir as operações de tradução ou apoiá-las quando um ator da iniciativa privada ou ONG a realize. $\mathrm{O}$ ator do poder público mais indicado 
para realizar as traduções é o extensionista pelo fato de poder estar em contato com os produtores, suas entidades e demais atores, como pesquisadores, representantes de ONGs e de setores privados da cadeia produtiva, por exemplo.

Controvérsia: a entrada real

Controvérsia pode ser definida como o debate, a polêmica que tem por objeto os fatos científicos, técnicos ou organizacionais que não estão ainda estabilizados. As controvérsias podem envolver, por exemplo, cientistas, extensionistas, governos, ONGS ambientais ou responsáveis por atividades que impactam o ambiente. Callon et al. (1999) afirmam que as controvérsias sociotécnicas têm dinâmicas que se estendem no tempo e no espaço. A trajetória de cada uma depende da sua natureza ou do nível de incertezas que portam, mas igualmente da forma como algumas acabam por serem reduzidas ou mesmo desaparecendo. O acompanhamento do desenvolvimento da controvérsia mostra os grupos sociais que entram em cena, as alianças que se estabelecem ligando as posições, as opções tecnológicas ou organizacionais que vão ser assumidas ou descartadas. As questões são refeitas, debatidas, na medida em que evolui a controvérsia. Elas são ao mesmo tempo a consequência e o motor da dinâmica.

Latour (2000) afirma que as controvérsias antecedem sempre um enunciado científico, inovação tecnológica ou organizacional. Portanto, o extensionista deve fazer um esforço para identificar as controvérsias existentes, para que seja feita a tradução entre os atores sociais envolvidos no problema e se estabeleça um acordo, para que a rede seja construída. $O$ autor define esse primeiro passo, ou seja, a detecção das controvérsias como "entrada real". Amblard et al. (2005), afirmam que a análise das controvérsias é o coração da sociologia da inovação, pois é por elas que se elaboram os fatos.

\section{$O$ fato e a rede}

O fato, ou seja, a mudança, a inovação, se viabiliza pela rede que o porta e esta somente existe devido ao próprio fato em torno do qual ela se forma. Fato e rede, respectivamente conteúdo e contexto, se viabilizam ou não sempre mutuamente. A solidez do fato depende da irreversibilidade da rede, ou seja, a sua legitimidade não é dada pelas suas qualidades, mas pela sua capacidade de arrebatamento, de construção de uma rede com a participação de diferentes atores.

O sucesso ou o fracasso de uma mudança, de uma inovação, não podem ser compreendidos a partir de suas propriedades intrínsecas. É o processo que ela foi objeto que permite compreender como foi adotada e que é a razão da sua emergência, que lhe dá ou não estabilidade. Portanto, a inovação não se impõe por si. Latour (2000) afirma que a construção de fatos, ou seja, de mudanças, é um processo coletivo, comparando a reconstituição das redes com a abertura de caixas pretas, em que se 
passa a compreender a lógica de ação dos atores e actants², seus papéis, a tradução e as interações estabelecidas entre todas as entidades individuais ou coletivas.

Exemplificando o presente conceito, pode-se considerar um caso em que o fato seja representado por um determinado modelo de criação de peixes, que só será adotado e viabilizado se, em torno dele, se formar uma rede integrada por técnicos, produtores, organizações de produtores, consumidores, fornecedores de insumos, a (s) espécie (s) de peixe (s) em questão, ONGs ambientais etc. Por outro lado, essa rede só seria possível de ser formada devido à existência do modelo de criação de peixes em questão. Mesmo que determinado técnico, produtor ou qualquer entidade acredite, proponha, insista em expor as qualidades de um determinado modelo de criação de peixes para que o mesmo seja adotado, ele somente existirá se um conjunto de atores sociais o viabilizarem. Os interesses de cada um são os fatores determinantes da construção da rede, não se tratando de convencimento de pessoas para integrá-la.

Simetria

Considerando que as entidades humanas e não humanas formam a rede, devese tratar com igualdade de importância os atores e actants, sejam eles humanos ou não. A importância de ambos é a mesma na construção e estabilidade da rede. Da mesma forma, o sucesso e o fracasso de uma atividade também devem ser tratados com a mesma importância, pois serão resultados dos fatores intrínsecos à rede.

\subsubsection{As dez etapas de construção de uma rede sociotécnica}

As redes sociotécnicas são construídas em dez etapas, que normalmente ocorrem na sequência apresentada, mas pode ocorrer uma etapa anteceder outra: análise do contexto, problematização, ponto de passagem obrigatório, atuação dos porta-vozes, investimento de forma, mobilização dos intermediários, mobilização dos atores, expansão e irreversibilidade da rede, vigilância e transparência. Assim, o extensionista para atuar como tradutor ou apoiar as traduções que são realizadas por outros atores, deve compreender como se constrói uma rede, de acordo com Amblard et al. (2005).

Amblard et al. (2005) contribuíram também elaborando uma proposição metodológica de operacionalização do instrumento de análise de construção de redes sociotécnicas, considerando uma cronologia em 10 etapas que, em determinadas situações, algumas delas não ocorrem uma após a outra, mas em simultaneidade. São elas: análise do contexto, problematização, ponto de passagem obrigatório, porta-vozes, investimento de forma, intermediários, mobilização, ampliação da rede, vigilância e transparência.

2 Latour (2000) define actant como qualquer coisa ou pessoa que na tradução é representada por porta-vozes. Por exemplo: determinada espécie de peixe que integra um modelo técnico de criação é um actant, visto que é desprovida de voz e deverá ser representada por um técnico, produtor ou outro ator que assimilará o papel de porta-voz 
A tradução se inicia com a contextualização que, nesse caso, é a compreensão dos atores implicados no processo, o interesse de cada um e o nível de convergência entre eles. A etapa seguinte é a da problematização, quando o papel do tradutor se destaca operando a ligação entre os atores do contexto em torno de uma questão geral, iniciando os seus deslocamentos no sentido da convergência, fazendo passá-los por um ponto de passagem obrigatório, que pode ser um enunciado, uma instituição, regras para a prática de determinada atividade ou um lugar.

Após as etapas descritas, o quadro entre as entidades é de cooperação. Considerando a rede o produto de uma negociação, cada entidade humana ou não humana tem o seu porta-voz nas discussões. Porém, dependendo do tamanho da rede, o ator-tradutor trata de reduzir o número de representantes para que haja maior homogeneidade e controle do processo. Essa etapa, denominada investimento de forma, é mais que um investimento material, é uma forma que permite um trabalho entre os diferentes atores. A rede é cimentada pelos intermediários, que significa tudo o que circula entre as entidades envolvidas, que as coloca em relação, podendo ser informações contidas em papéis, disquetes, informativos técnicos, dinheiro ou outros seres humanos com as suas competências.

A cooperação entre os atores está estabelecida, a ligação dos porta-vozes está feita. Agora, os atores serão alistados e mobilizados, tendo um sentido, um papel ativo definido para fazer a rede sociotécnica funcionar. A expansão da rede é fundamental para a sua estabilidade e irreversibilidade, que ocorre no sentido do seu centro em direção à periferia, agregando novos atores que lhe darão mais solidez e viabilização do fato.

A estabilidade da rede depende, também, da sua vigilância. É necessário que esta seja feita em diferentes aspectos para que não haja o enfraquecimento da rede, que pode ser causado por um problema externo, como o surgimento de um patógeno que provoque grandes perdas aos piscicultores, por exemplo, ou, ainda, a perda de mercado para produtores de outra região. A vigilância deve ser feita da mesma forma sobre o comportamento dos atores da rede, para que não haja traição, causada principalmente por atores que mudam de papel no decorrer do tempo e passam a perseguir objetivos de caráter pessoal. Portanto, a transparência deve ser constante em todo o processo de construção da rede para que não gere dúvidas. $A$ confiança entre os atores está fundamentada nas suas ações. A existência da mínima manipulação pode condenar a tradução e sepultar a rede.

\subsection{Economia de proximidade}

As diferentes proximidades observadas em determinado território, como: cultural, geográfica, institucional e organizacional (Martin, 2010; Torre e Filippi, 2005) podem ser fatores determinantes para viabilizar empreendimentos econômicos 
solidários, visto que facilitam a organização dos agricultores e demais integrantes de uma cadeia produtiva para que assumam a postura de colaboração e de valorização dos recursos locais. As proximidades podem viabilizar as interações solidárias entre indivíduos e organizações em um determinado território.

\subsubsection{Tipologia das proximidades}

\section{Proximidade cultural}

A proximidade cultural é verificada em territórios onde as pessoas têm características comuns, como comunidades tradicionais - indígenas e quilombolas - descendentes de imigrantes do mesmo país ou região e territórios onde há uma expressiva concentração de agricultores familiares. As práticas adotadas no seio dessas comunidades são fundamentalmente do mundo doméstico, como organização de festas, rituais religiosos, respeito à sabedoria dos mais velhos e hierarquia. Em alguns casos utilizam idioma próprio e práticas agrícolas tradicionais, com poucas inovações.

Efetivamente, a proximidade cultural pode ser um fator que facilita a organização em associações e cooperativas e o desenvolvimento de práticas cívicas, mas, por outro lado, a tradição pode dificultar a adoção de inovações que possibilitam o acesso ao mercado, a interação entre os mundos doméstico e mercantil, podendo haver geração de conflitos. O extensionista, utilizando-se de metodologia participativa, pode promover palestras, cursos, estudos de mercado e excursões para que os grupos conheçam a realidade de outros agricultores que acessaram o mercado com sucesso.

É importante ressaltar que em territórios onde os produtores não possuem proximidade cultural, não está inviabilizada a possibilidade de se ativar outras proximidades, fundamentalmente aquelas relacionadas com 0 interesse de se organizar para buscar soluções de forma coletiva.

\section{Proximidade geográfica}

A proximidade geográfica pode ser um fator de grande importância para a construção de relações solidárias entre agricultores familiares, por exemplo. Para que se torne uma vantagem competitiva, as relações que podem ser facilitadas por esse tipo de proximidade devem ser ativadas. É o caso de um determinado território em que há piscicultura e existe produtor de alevinos, piscicultores que se dedicam à engorda de peixes, fabricante de ração, pesque-pagues que compram o pescado, extensionistas, enfim, os principais agentes que constituem a cadeia produtiva da atividade, mas cujas relações limitam-se ao mundo mercantil. Desta forma, não se aproveita a proximidade geográfica existente para o estabelecimento de coesão social e relações solidárias que propiciem ganhos financeiros e de aprendizagem para todos os integrantes da cadeia, de forma equitativa. Assim, a questão que emerge é: como ativar a proximidade geográfica? 
Inicialmente é necessário que os piscicultores estejam associados ou cooperados e sejam desenvolvidas ações como mutirões de despesca, fundos rotativos, reuniões para troca de informações referentes às técnicas e insumos utilizados e os resultados dos ciclos de produção. Os representantes dos fornecedores e compradores devem ser convidados para participar dos eventos. Assim, criam-se possibilidades para que a proximidade geográfica seja um facilitador para a proximidade organizacional entre os agentes da cadeia produtiva, promovendo a redução de custos e aperfeiçoamento dos produtos com base nas necessidades dos consumidores. Possibilita-se, ainda, a organização da cadeia produtiva de forma que haja uma distribuição mais equitativa da renda gerada e agregação de valor aos produtos, associando-os ao território ou à forma de produção.

\section{Proximidade institucional}

A proximidade institucional é representada, principalmente, pela interação das ações dos profissionais do poder público que atuam em determinado território em apoio aos empreendimentos econômicos solidários. Esse tipo de proximidade é determinante para o sucesso das atividades, sendo que o ideal é que pesquisadores e extensionistas atuem no mesmo órgão ou integrem um fórum de economia solidária local onde possam definir suas ações de forma conjunta, contando ainda com a participação dos agricultores. Integrando o mesmo órgão ou um fórum, a interação entre os referidos profissionais será facilitada. É determinante, também, que haja proximidade de outros profissionais, como representantes de agências de financiamento e de órgãos do meio ambiente, responsáveis pela elaboração de leis e pela fiscalização de sua aplicação. Os produtores, por meio da direção das entidades, com o apoio dos extensionistas, pode solicitar reuniões periódicas entre os atores ligados ao poder público para debater processos, resultados, problemas e soluções.

\section{Proximidade organizacional}

A proximidade organizacional também deve ser ativada e pode ser representada pelas cooperativas e/ou associações de produtores em relação de cooperação com outros segmentos da cadeia produtiva, extensionistas e pesquisadores. A proximidade organizacional é preeminente em relação a qualquer outro tipo de proximidade, seja ela cultural, geográfica ou profissional. Martin (2010) afirma que a vitalidade econômica de uma atividade ou território é incontestável quando se constrói a proximidade organizacional, visto que os atores passam a trabalhar de forma coordenada e a mutualizar seus recursos, o que requer o estabelecimento de relações de confiança, reciprocidade e solidariedade, características fundamentais da economia solidária.

Para que se tenha proximidade organizacional entre empreendimentos econômicos solidários, fornecedores, consumidores e profissionais do poder público de determinado território, é necessário que os agricultores familiares estabeleçam proximidade organizacional nas associações e cooperativas por meio de trocas de 
informações sobre os resultados alcançados, exposição de problemas, busca de soluções de forma coletiva e desenvolvimento de ações de cooperação na compra de insumos e comercialização da produção.

\subsubsection{Ativar e fazer interagir as proximidades}

Há territórios em que já existem proximidades e não são ativadas em benefício dos empreendimentos econômicos solidários, pois falta visão dessa possibilidade e cooperação, sendo as relações fundamentadas somente no mundo mercantil. Nesses casos, os pesquisadores e extensionistas devem realizar estudos socioeconômicos para compreender a existência de proximidades e propor formas de cooperação que possam ativá-las e fazer com que as interações ocorram. Torre e Beuret (2012) afirmam que a proximidade geográfica quando interage com a proximidade organizacional de determinada atividade emerge a proximidade territorial, como demonstrado na Figura 6, situação em que se inicia um processo de inserção da atividade na governança do território.

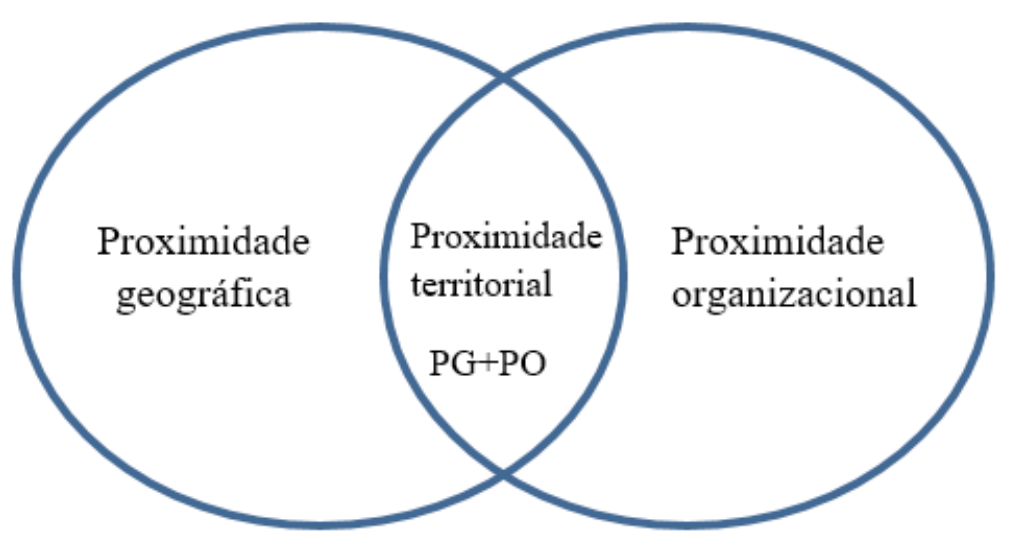

Figura 6. Representação da interação entre as proximidades geográfica e organizacional Fonte: Torre e Beuret (2012)

Assim, emerge o desafio de fazer interagir as proximidades que poderão viabilizar os empreendimentos econômicos solidários em determinado território por meio da cooperação e reciprocidade e incluir a economia solidária nos processos de governança territorial. A identificação do território com a economia solidária contribui para o desenvolvimento local e pode gerar vantagens competitivas baseadas na agregação de valor, podendo ser comercializado como "produto originário de relações solidárias". O reconhecimento e apoio de diferentes segmentos da sociedade são de fundamental importância para a sustentabilidade dos empreendimentos econômicos solidários. O extensionista, além da assistência técnica aos produtores, pode ser o articulador e animador do processo. 


\section{I RECOMENDAÇÕES PARA O FORTALECIMENTO DA ECONOMIA SOLIDÁRIA}

A economia solidária fundamentada no associativismo e/ou cooperativismo é a forma de organização mais observada. Os diferentes órgãos e políticas do poder público devem ser integrados para apoiar essas organizações. Assim, criam-se condições para a emergência de inovações técnicas e organizacionais necessárias para a superação de eventuais crises, fenômeno comum na sociedade capitalista, e, ao mesmo tempo, haja condições para acessar o mercado com fundamentação nas relações de solidariedade e reciprocidade. Então, há três aspectos que devem estar em interação: a organização dos agricultores, ação do poder público e adequação dos produtos às necessidades do segmento do mercado consumidor a que se destinam. Dessa forma, são apresentadas algumas recomendações para o poder público, pescadores artesanais, indígenas, quilomobolas e agricultores familiares atuarem com o objetivo de fortalecer a economia solidária:

- disponibilizar um serviço multidisciplinar de extensão

É necessário que haja um serviço multidisciplinar para que se que atenda às diferentes exigências da economia solidária. A atuação do extensionista não pode ser fundamentada na difusão de tecnologia. A sua ação deve contemplar o assessoramento técnico e organizacional baseado no construtivismo, com a valorização da participação. É de fundamental importância que os extensionistas atuem para a capacitação continuada do público para a gestão de negócios, associativismo e cooperativismo, valores e princípios da economia solidária e para o acesso às políticas públicas.

As ações de extensão devem estar voltadas, também, para elevar o capital social das comunidades onde se objetiva promover o desenvolvimento socioeconômico. O capital social, pelo fato de viabilizar ações colaborativas, tem um peso fundamental para a obtenção de resultados positivos para toda a comunidade (Putnam, 2002). Entendese que o capital social é formado pela presença de três fatores em interação: confiança, normas e cadeias de reciprocidade e sistema de participação cívica (D’Araújo, 2003). As sinergias emergentes da confiança e reciprocidade existentes entre agricultores (capital social comunitário), com a pertinência e coerência das ações do poder público (capital social institucional) e as relações estabelecidas entre produtores de diferentes regiões por meio da troca de experiências (capital social extra-comunitário) (Woolcock, 1998, apud Moraes, 2003), podem contribuir de forma decisiva para o desenvolvimento da economia solidária. Assim, o serviço de extensão tem também o importante papel de identificar os produtores que possuem as mesmas preocupações e anseios, a fim de estimular aproximações e atuar como articulador dos diferentes atores que devem integrar a rede sociotécnica que viabilizará o empreendimento econômico solidário.

- realizar pesquisa-ação

A pesquisa deve ser realizada com a inserção dos agricultores em todas as 
etapas da adaptação ou geração de tecnologia, valorizando os seus conhecimentos empíricos e necessidades. A atuação deve ser feita por uma equipe multidisplinar de pesquisadores, obrigatoriamente integrada às dinâmicas locais.

- elaborar projetos de forma participativa

Os projetos devem ser elaborados de forma participativa. Os agentes do poder público têm que considerar sempre um dos princípios fundamentais da sociologia da tradução: "nenhum projeto se impõe por suas qualidades próprias, são as redes sociotécnicas que os viabilizam" (Amblard et al., 2005). Projetos que representam somente a lógica de um técnico, liderança comunitária ou poder público, têm elevada probabilidade de não apresentarem resultados positivos.

\section{I CONCLUSÃO}

A extensão rural adotou o difusionismo como forma de trabalho para viabilizar, principalmente, a adoção de técnicas. Porém, com a emergência do conceito de sustentabilidade, emergiu também a necessidade de se formar extensionistas que sejam capazes de conhecer os aspectos técnicos das culturas e criações e tenham habilidade para colocar em relação diferentes atores sociais para a construção de redes e, consequentemente, viabilizar projetos, ideias e soluções de forma participativa. $O$ conhecimento e adoção de referenciais teóricos integrantes do construtivismo são necessários, principalmente, no que concerne à construção da economia solidária por agricultores familiares, pescadores artesanais, indígenas e quilombolas. Assim, as universidades deveriam se engajar no processo de formação de profissionais com um novo perfil. Os órgãos de extensão deveriam priorizar o construtivismo como referência de atuação. Então, haveria mais possibilidades de inclusão socioeconômica para comunidades rurais e litorâneas com fundamentação nos valores e princípios da economia solidária.

\section{REFERÊNCIAS}

ANDRADE, J.C. ; DIAS, C.C. ; QUINTELLA, R.H. A dimensão político-institucional das estratégias sócio ambientais : o jogo Aracruz Celulose S.A. - Índios Tupiniquim e Guarani. Ambiente e Sociedade, Campinas, ano IV, $n^{\circ}$ 9, 1 - 18. 2001.

AMBLARD, H.; BERNOUX, P.; HERREROS, G.; LIVIAN, Y.F. Les nouvelles approches sociologiques des organisations. $3^{\mathrm{a}}$ ed. Paris: Seuil, 2005. 244p.

BATALHA, M.O. Gestão do agronegócio. São Carlos: Edufscar. 465 p.

BERNOUX, P. Sociologie du changement : dans les entreprises et les organisations. Paris : Éditions Du Seuil. 2004. 308 p.

BEURET, J. E. La conduite de la concertacion pour la gestion de l'environnement et le partage des 
resources. Paris: Éditions L’Harnattan, 2006. 322p.

BOLTANSKI, L.; THÉVENOT, L. De la justification. Les économies de la grandeur. Paris: Gallimard, 1991. $482 \mathrm{p}$.

BROSE, M. Metodologia participativa. Porto Alegre: Tomo Editorial. 2001. 310p.

CALLON, M. Eléments pour une sociologie de la traduction: la domestication des coquilles SaintJacques et des marins-pêcheurs dans la baie de Saint-Brieuc. L'Anné Sociologique, 1986. n 36. p. 169-208.

CALLON, M. Por uma nova abordagem da ciência, da inovação e do mercado. O papel das redes sociotécnicas. IN: PARENTE, A. Tramas da rede. Porto Alegre: Editora Sulina. 2010. 64 - 79p.

CALLON. M. Le réseau comme forme émergente et comme modalité de coordination : les cas des interactions stratégiques entre firmes industrielles et laboratoires académiques. IN : CALLON, $M$; COHENDET, P., CURIEN, N., DALLE, J. M., EYMARD DUVERNAY, F., FORAY, D., SCHENK. Réseau et coordination. Paris: Economica. 1999. $13-64$ p.

CAPORAL, F.R. A extensão rural e os limites à prática dos extensionistas do serviço público. 1991. 134 p. Dissertação (Mestrado em Extensão Rural). Universidade Federal de Santa Maria. Santa Maria, RS. 1991.

CAPORAL, F.R. La extensión agrária del sector público ante los desafios del desarollo sostenible: el caso de Rio Grande do Sul, Brasil. 1998. 517 p. (Tese de Doutorado). Programa de Doctorado en Agroecologia, Campesinado e História, ISEC-ETSIAN, Universidad de Córdoba, Córdoba. 1998.

COLOMBO, E. A. Contribuição e Proposta da Emater-RS, construindo o modelo Alternativo de Desenvolvimento Rural e Extensão Rural. 2000. 196 p. Dissertação (Mestrado em Extensão Rural). Universidade Federal de Santa Maria, Santa Maria, 2000.

CORCUFF, P. Les nouvelles sociologies. Paris : Nathan. 1995. 126 p.

D’ARAUJO, M.C. Capital social. Rio de Janeiro : Jorge Zahar. 2003. 65 p. (Passo a Passo, 25).

DAVIS, J.H.; GOLDBERG, R.A. A Concept of agribusiness. Boston: Division of Research. Graduate School of Business Administration. Harvard University, 1957. 136p.

FASER. Uma nova assistência técnica e extensão rural centrada na agricultura familiar: proposta. Trabalho apresentado no Workshop Nacional: "Uma Nova Assistência Técnica e Extensão Rural Centrada na Agricultura Familiar". Brasília, DF, 24-28 de novembro de 1997, Brasília, DF.

FONSECA, M.T.L. A extensão rural no Brasil, um projeto educativo para o capital. SãoPaulo: Edições Loyola, 1985, $192 \mathrm{p}$.

FOURNIER, S. ; MUCHNICK, J. ; REQUIER-DESJARDINS, D. Proximité et efficacité collective : les cas des filières gari et huile de palme au Bénin. IN TORRE, A ; FILIPPI, M. Proximités et changements socio-écnomiques dans les mondes ruraux. Paris : INRA. 2005. 319 p. (un point sur...).

FREIRE, P. Extensão ou comunicação? Paz e Terra. Rio de Janeiro: Paz e Terra, 1980, 93 p.

HEGEDUS, P. La extensión rural em Uruguay. In: Vela, H.A.G. Extensão rural no Mercosul. Cruz Alta: Unicruz, 1999, $72 \mathrm{p}$.

LAMBALLE, P.; CASTELLANET, C. La recherche-action em milieu paysan: méthodes et outils. Paris: Les Éditions du GRET, 2003. 168 p. 
LATOUR, B. Ciência em ação : como seguir cientistas e engenheiros sociedade afora. São Paulo: UNESP. 2000. 438p.

LEITE, E.S.; Silva, J.S.; Silva, J.G.S.; Magalhães, T. Extensão rural e pesqueira agroecológica amazônica: a experiência do projeto Piraruci-Gente. Apresentado no XV Encontro de Ciências Sociais do Norte e Nordeste e Pré-ALAS Brasil. 04 a 07 de setembro de 2012. Universidade Federal do Piauí, Teresina, Piauí. Capturado no endereço http://www.sinteseeventos.com.br/ciso/anaisxvciso/resumos/ GT22-03.pdf em 10/03/2013.

MPA. Assistência técnica e associativismo. Capturado em 20/03/2013. http://www.mpa.gov.br/index. php/infraestrutura-e-omentompa/fomento/assistencia-tecnica-e-associativismo.

LIMA, I. A. A Extensão Rural e a produção do conhecimento: a fundamentação científica dos Planos Municipais de Desenvolvimento Rural do Programa Nacional de Fortalecimento da Agricultura Familiar (Pronaf) no Estado de São Paulo. 2001. 127 p. Dissertação. Mestrado em Planejamento e Desenvolvimento Rural Sustentável. Faculdade de Engenharia Agrícola. Universidade Estadual de Campinas.Campinas/SP.

LÜDKE, M.; ANDRÉ, M.E.D.A. Pesquisa em educação: abordagens qualitativas. Rio de Janeiro: E.P.U. 2013. 112p.

MARTIN, P.M. L'économie de proximité: une réponse aux défis majeurs de la societé française. Paris: Conseil Économique, Social et Environnemental. 2010. 190 p.

MORAES, J. L.A. de. Capital social e desenvolvimento regional. p. 123-148. IN : CORREA, S.M.S. Capital social e desenvolvimento regional. Santa Cruz do Sul : EDUNISC. 2003. 334p.

NUNES, D. Incubação de empreendimentos de economia solidária. São Paulo: Annablume. 2009. $350 \mathrm{p}$.

OLINGER, G. Ascensão e decadência da extensão rural no Brasil. Florianópolis: EPAGRI, 1996, 523 p.

PINTO, A.G. A construção de uma nova extensão rural: o potencial dos técnicos da rede pública de São Paulo. 1998. 114 p. Dissertação. Mestrado em Planejamento e Produção Agropecuária. Faculdade de Engenharia Agrícola. Campinas. Universidade Estadual de Campinas. Campinas. 1998. PUTNAM, D. R. Comunidade e democracia: a experiência da Itália moderna. 3.ed. Rio de Janeiro: Fundação Getúlio Vargas. 2002. 260 p.

RODRIGUES, C. M. Conceito de seletividade de políticas públicas e sua aplicação no contexto da política de extensão rural no Brasil. Cadernos de Ciência e Tecnologia, Brasília, v. 14, n. 1, 1997, p. $113-154$.

SILVA, N.J.R. Dinâmicas do desenvolvimento da piscicultura e políticas públicas: análise dos casos do Vale do Ribeira (SP) e do Alto Vale do Itajaí (SC).São Paulo: Editora UNESP, 2008, 240 p.

SILVA, A.P.; Oliveira, J.T.A. O modelo cooperativo de extensão dos Estados Unidos: contribuições possíveis para o Brasil. Rev. Ceres, Viçosa, v. 57, n. 3, p. 297 - 306. 2010.

TORRE, A.; FILIPI, M. Proximités et changements sócio-économiques dans les mondes ruraux. Paris: INRA Éditions. 2005. 322 p.

TORRE, A.; BEURET, J-E. Proximités territoriales. Paris: Economica, 2012. 105 p.

VAN DER BAN, A. W. e HAWKINS, H. S. Extensión agraria. Editorial Acribia. Zaragoza. 1998. 340 p. 
VELA, H.A.G. e HEGEDUS, P. A extensão rural e o pensamento internacional. In: Vela, H.A.G. Extensão rural no Mercosul. Cruz Alta: Unicruz, 1999, 72 p. 